\title{
The Effects of Partnership-Based Collaborative Consultation on Treatment Integrity, Increasing Skill Acquisition, and Reducing Problematic Behaviors
}

\author{
Michael Mendicino
}

Follow this and additional works at: https://researchrepository.wvu.edu/etd

\author{
Recommended Citation \\ Mendicino, Michael, "The Effects of Partnership-Based Collaborative Consultation on Treatment Integrity, \\ Increasing Skill Acquisition, and Reducing Problematic Behaviors" (2015). Graduate Theses, Dissertations, \\ and Problem Reports. 6214. \\ https://researchrepository.wvu.edu/etd/6214
}

This Dissertation is protected by copyright and/or related rights. It has been brought to you by the The Research Repository @ WVU with permission from the rights-holder(s). You are free to use this Dissertation in any way that is permitted by the copyright and related rights legislation that applies to your use. For other uses you must obtain permission from the rights-holder(s) directly, unless additional rights are indicated by a Creative Commons license in the record and/ or on the work itself. This Dissertation has been accepted for inclusion in WVU Graduate Theses, Dissertations, and Problem Reports collection by an authorized administrator of The Research Repository @ WVU. For more information, please contact researchrepository@mail.wvu.edu. 
The Effects of Partnership-Based Collaborative Consultation on Treatment Integrity, Increasing Skill Acquisition, and Reducing Problematic Behaviors

\title{
By
}

\author{
Michael Mendicino
}

\begin{abstract}
Dissertation submitted to the College of Education and Human Resources
At West Virginia University

In partial fulfillment of the requirements for the degree of
\end{abstract}

\author{
Doctor of Education \\ In \\ Educational Psychology \\ Approved by \\ Daniel E. Hursh, Ph.D., Chair \\ Neal Shambaugh, Ph.D. \\ Ann P. Richards, Ph.D. \\ Christine Schimmel, Ed.D. \\ Neil T. Heffernan, Ph.D. \\ Department of Technology, Learning, and Culture
}

Morgantown, West Virginia

2015

Keywords: Autism, Applied Behavior Analysis, Collaborative Consultation, Competent Learner Model, Single Case Research Design

Copyright 2015 Michael Mendicino 


\begin{abstract}
The effects of partnership-based collaborative consultation on treatment integrity, increasing skill acquisition, and reducing problematic behaviors
\end{abstract}

The purpose of this study was to evaluate the impact of a partnership-based model of collaborative consultation on the acquisition and implementation integrity of Competent Learner Model and the subsequent impact on learner outcomes including the development of competent learner repertoires. Treatment integrity measures were collected to assess the impact on learner outcomes. The participants were one teacher and one student. A Multiple baseline across behaviors design was used. Measures used were the Partnership Assessment in Communitybased Research (PAIR), and the Instructional Session Performance Checklist (ISPC). The results showed moderate and sustained levels of treatment integrity with mixed results for learner outcomes. Implications of the research suggest that a partnership-based collaboration can support a teacher in acquiring evidence-based practices. 


\section{TABLE OF CONTENTS}

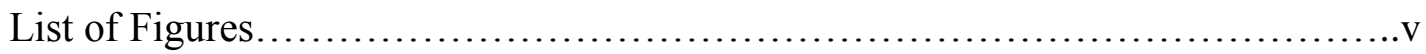

List of Tables.....................................................................

Acknowledgements...................................................... vii

Chapter 1: Introduction......................................................

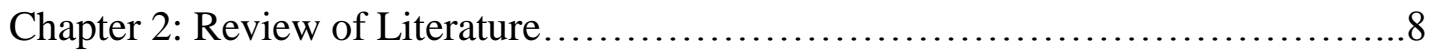

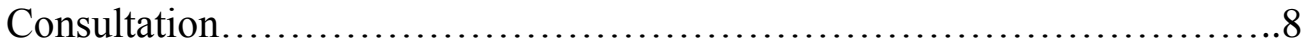

Participatory Intervention Models..................................... 17

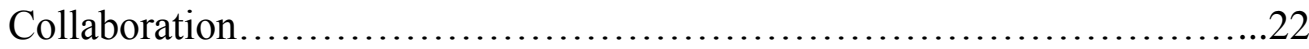

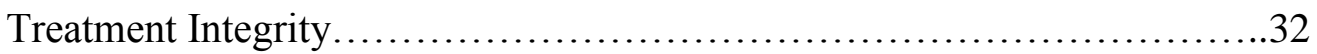

Current State of Autism Interventions..................................47

Evidence-Based Practices................................................52

Competent Learner Model...............................................56

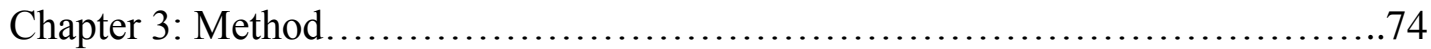

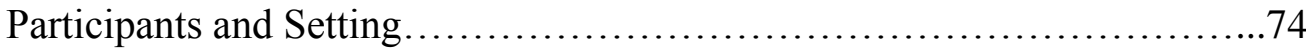

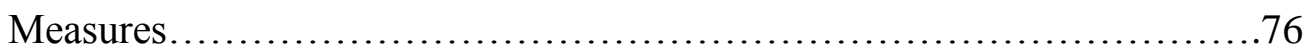

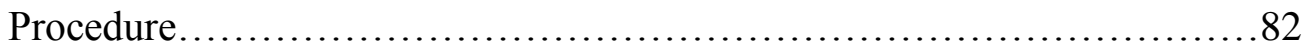

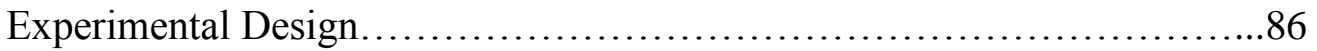

Chapter 4: Results...................................................... 91

Research Question One...........................................91

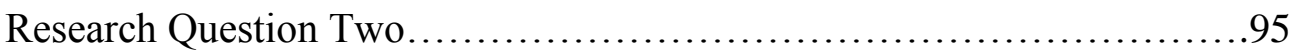

Research Question Three...............................................97

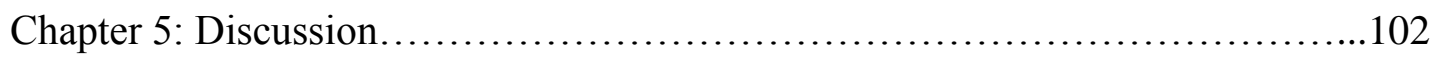

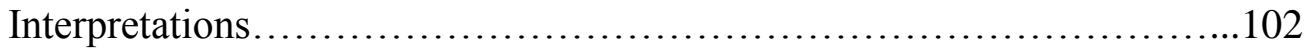

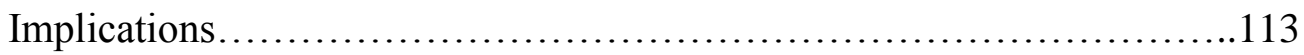

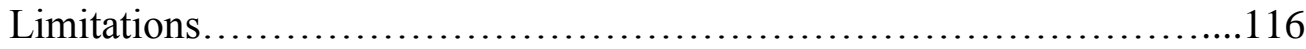

Conclusion........................................................ 117

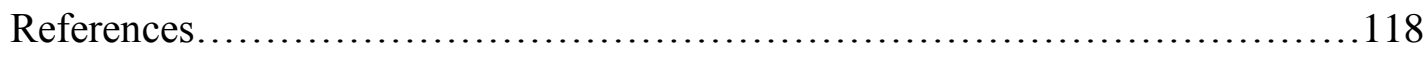

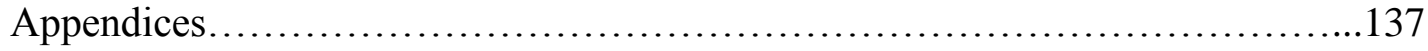




\section{LIST OF FIGURES}

Figure1. Comparison of PAIR dimension means for each administration........87

Figure2. Total PAIR means for each administration........................88

Figure3. Baseline and Intervention Measures of Problematic Behaviors........93 


\section{LIST OF TABLES}

Table 1 Summary of Properties of Measures...........................73

Table 2 Consultation Phases and Tasks.............................. 80

Table 3 Means and Percentages for PAIR across Administrations...........86

Table 4 Treatment integrity of Competent Learner Model.................90

Table 5 Percent Non-Overlapping Data and Standard Mean Difference Scores.................................................................94 


\section{ACKNOWLEDGEMENTS}

The author wishes to thank Dr. Daniel E. Hursh for his guidance and helpful comments. 


\section{DEDICATION}

The author wishes to dedicate this study to his family and to all the dedicated teachers who work with students with disabilities every day. 


\section{CHAPTER 1}

Introduction

Autism is a neurodevelopmental disorder characterized by deficits in social communication development accompanied by stereotyped, repetitive, and restricted patterns of behavior and interest (American Psychiatric Association, 2013). The DSM-V classifies autism along with pervasive developmental disorder-not otherwise specified (PDD-NOS) and Asperger syndrome as pervasive development disorders. All three are referred to collectively as Autism spectrum disorder (ASD).

The number of students identified with autism in the public schools has increased steadily. For example, in 2012 the Prevention Network for Monitoring Autism and Developmental Disabilities (ADDM) which is associated with the Center for Disease Control (CDC) estimated that 1 in 88 children were identified with Autism (CDC, 2012). This was an increase of $23 \%$ in prevalence rates form 2006 when 1 in 110 were identified. The prevalence in boys was much higher with 1 in 54 boys being identified as having ASD compared to the prevalence rate for girls which stands at 1 in 252 girls. The most recent data on prevalence rates from the Center for Disease Control (March, 2014) puts the prevalence at 1 in 68 children with 1 in 42 boys and 1 in 189 girls now identified with autism spectrum disorder. Researchers at the National Center for Health Statistics (Blumberg et al., 2013) suggest that among school age children, ages 6-17, the prevalence of those diagnosed with ASD is closer to 1 in 50. Additionally, in Asia, Europe, and North America the average prevalence rate is $1 \%$, while in South Korea the prevalence is much higher with $2.64 \%$ of South Korean children between ages 7 to 12 diagnosed with ASD (American Journal of Psychiatry, $2011 \mathrm{Kim}, \mathrm{YS}$, et al.). 
Schools are legally required to provide and implement with fidelity interventions that have been developed and proven effective through scientifically based research (IDEA, 2006; NCLB, 2002). However, the increase in students diagnosed with autism has not been accompanied by an increase in research-based practices used within classrooms. Indeed, while the number of available interventions for students with autism has increased many are not grounded in sound research, and are thus nominally effective and occasionally completely ineffective (Koegel, Robinson, \& Koegel. 2010). This is inexcusable because children with ASD do not tolerate mistakes as readily as typical children and thus require the most effective interventions Dammann \& Vaughn (2001). McGee and Morrier (2005) further point out that children with ASD require precise and systematic implementation of instructional strategies and practices found to be effective through sufficient research in order for optimal learning, Currently the most researched and recommended treatment strategies for students with autism are those based on behavioral principles, typically found in applied behavior analysis (Eikeseth, Smith, Jahr, \& Eldevik, 2002; Sallows \& Grauper, 2005), behavioral psychology literature, and positive behavior supports (National Standards Project, 2009), but these interventions are lacking in most classrooms.

There are many examples in the literature to support the need for teachers to be trained in EBPs. It is alarming that even with the rapid increase in autism rates and the availability of scientifically proven practices; a majority of classrooms for students with autism are not providing programs and interventions that are based on scientifically sound research (Hess, Morrier, Heflin, and Ivey, 2008). Many classrooms for students with autism employ interventions lacking demonstrated effectiveness with up to $40 \%$ of interventions not listed at evidence-based (Simpson et al., 2005). As a result, individuals with autism continue to have 
difficulty in school with academics, social skills, communication, and challenging behaviors (Carter, Lane, Cooney, Weir, Moss, \& Machalicek, 2013). Several factors may account for this, but recent research has revealed that teachers of students with autism report possessing very low levels of knowledge about characteristics of autism and low levels of confidence in implementing evidence-based practices (Morrier, Hess, and Heflin, 2011). In their survey of 90 teachers Morrier et.al, (2011) reported that only 5\% of teachers consistently used evidence-based practices in their classrooms. Supporting this claim, Brock and colleagues (2014) surveyed 456 teachers about professional development needs in educating students with autism and found that teachers reported very low confidence when asked about their perceived ability to implement evidence-based practices.

Additionally, teachers report receiving inadequate preparation in evidence-based interventions during both pre-service and in-service training and feeling ill prepared to deal with the complex nature of autism (Morrier, Hess, and Heflin, 2011). Recent efforts of teacher preparation programs to include autism related coursework in which evidence-based practices are included in the curriculum have proven to be highly variable in quality and outcomes (Barnhill, Polloway, \& Lee, 2013). Typical in-service trainings have not fared much better with the usual workshop format that offers little, if any support and follow-up has not improved the quality or accuracy of evidenced-based practices in classrooms (Hall, Grundon, Pope, \& Romero, 2010). Individualized coaching and mentoring models are more effective, but are rarely used in schools (Kretlow \& Bartholomew, 2010). The lack of appropriately trained personnel has been cited as a major barrier to effective treatments and the availability of quality services in schools (Loiacono \& Allen, 2008). While recent research reviews have demonstrated the efficacy and research base for focused interventions (Odom, Collet-Klingenberg, Rogers, and Hatten, 
2010) and broader educational practices (National Autism Center, 2009), getting those practices into the classroom remains difficult and one major factor is the continuing research to practice gap (Snell, 2003). Teachers sometimes secure their jobs without the benefit of formal educational training in evidence-based interventions. In addition, they typically receive only minimal job support and training (Katsiyannis, Hodge, \& Lanford, 2000) and thus are in need of some type of training opportunities to ensure consistent, successful, and sustainable implementation of empirically based strategies. Clearly, teachers need specific training in evidence-based practices to make an impact and improve the educational outcomes for their children.

Researchers are considering ways to train teachers already in the classroom as effectively and efficiently as possible. For example, Kohler, Anthony, Steighner, and Hoyson (2001) examined peer coaching in which teachers worked with other teachers and provided each other with feedback and on-the-spot suggestions both on a daily as well as weekly basis. They found that these strategies improved teachers' skills and instruction. In the context of considering student achievement through staff development, Joyce and Showers (2002) found that the addition of peer coaching that involved collaborative planning and development to training procedures above and beyond acquisition of skills and knowledge facilitated the transfer of training into practice which in turn impacted student learning. This method focuses on improving the science to practice gap. Snell \& Janney (2000) found that teacher collaboration and problem solving strategies embedded within the classroom environment and routines were highly effective and most likely essential in training teachers.

Behavioral Consultation based on behavior principles, has been shown to be an effective indirect service delivery model and is the most widely used model in schools (Bergan \& 
Kratochwill, 1990). Because behavioral consultation follows a specific sequence and is operationalized through a four-stage problem solving process with a clear linear structure it has received the most empirical and clinical attention to date.

However, several limitations have been associated with this approach. For one, the traditional process of behavioral consultation has been largely expert-driven, as consultants define and create interventions without input from stakeholders including teaches (Kelleher et al, 2007). The "expert" instructs consultees in pre-developed strategies and expects strict adherence and accuracy in implementation. There is little flexibility for consultees in implementing interventions, little ownership in interventions, and little empowerment on the part of consultees. While this approach has given teachers access to research supported interventions, they oftentimes feel alienated due to the lack of input (Shulte \& Osborne, 2003).. As a result, the consultant's advice and suggested interventions are not always sustained over time in the classroom (Nastasi et. al., 2000). Limited input from important stakeholders such as teachers and parents also results in interventions that often lack social and cultural validity and are not always acceptable to consultees (Shulte \& Osborne, 2003). As a result, the interventions are not sustainable, and are not implemented with appropriate treatment fidelity and duration needed to be effective (Nastasi et. al., 2000).

Several researchers (Leff et. al., 2006; Power et. al., 2005) suggest that researchers need to develop a collaborative partnership that combines the expertise and strengths of both researcher and teacher in order to develop ecologically valid and sustainable interventions (Leff et al, 2006). This approach also has the potential to promote capacity building and may result in more ecologically valid and sustainable interventions. Teachers sometimes secure their jobs without the benefit of formal educational training in evidence-based interventions. In addition, 
they typically receive only minimal job support and training (Katsiyannis, Hodge, \& Lanford, 2000) and thus are in need of some type of training opportunities to ensure consistent, successful, and sustainable implementation of empirically based strategies. The question remains, what are the most effective and efficient methods to train teachers in EBPs that are responsive to their needs and will result in interventions that are sustainable and delivered with high levels of treatment integrity.

The purpose of this current study is to investigate the effects of a partnership-based approach to collaborative consultation on multiple dimensions of treatment integrity (adherence, exposure, quality of delivery, participant responsiveness) of evidence-based autism interventions as implemented by teachers. In addition, the present study will explore the impact of partnershipbased collaboration on the acceptability and sustainability of interventions. Finally, this study will explore the impact of partnership-based collaboration on change in child learning outcomes during consultation.

The research questions for this study were:

1) What level of partnership was achieved between the researcher and teacher-participant and how did the relationship change on key partnership dimensions of communication, collaboration, partnership values, benefits, and evaluation during the course of intervention implementation?

2) What level of treatment integrity did the teacher attain when implementing the competent learner model when provided with partnership-based collaborative consultation and did changes in the collaborative relationship impact treatment integrity? 
3) What was the impact of implementation of competent learner repertoires selected through partnership-based collaboration on learner outcomes? 


\section{CHAPTER 2}

\section{Literature Review}

First, models, theories, and research findings for consultation and collaboration in the school community will be examined from initial expert behavioral models to partnership-based collaborative models. Second, treatment integrity and its relation to consultation and collaboration will be reviewed including initial conceptions of treatment adherence models and extending to recent multidimensional conceptions of treatment integrity. Third, the National Standard Project's analysis of evidence-based interventions for students with autism will be reviewed. Next, non-behavioral and behavioral interventions typically found in classrooms for students with autism will be explored. Finally, a description and analysis of the Competent Learner Model (CLM) will be provided including theoretical foundations, key components, and empirical support.

\section{Consultation}

Consultation has broad meanings across medical, psychological, and educational settings and exists in multiple forms including mental health consultation (Caplan, 1970), organizational consultation (Schmuck, 1990), and behavioral consultation (Bergan \& Kratochwill, 1990). In contrast to traditional practice in which an expert works directly with clients to solve problems and provide treatment, consultation is defined as an indirect problem-solving and decisionmaking process that usually involves at least two people joining forces on behalf of a thirdparty individual (Sheridan \& Kratochwill, 1990). When applied specifically to school settings, Sheridan and Cowan (2004) suggest that consultation involves problem-solving that is collaborative between an expert consultant, usually a school psychologist or school counselor 
and one or more persons or consultees that may include anyone responsible for the students' well-being such as parents, teachers, or paraeducators. The goal of consultation is to ultimately produce change in the child's behavior by first changing consultee's behavior. Consultants in schools have expanded to include not only school psychologists, but also speech pathologists and special education teachers (Gutkin \& Curtis, 1998).

\section{Structured Behavioral Consultation}

Most school-based consultation derives from behavioral theory and applied behavior analysis and involves academic, social or behavior issues. There are two primary goals for those providing consultation through indirect service-delivery models: The first, the intervention goal, aims to resolve the student's problem in the short term the second, the prevention goal, is the more long-term goal which seeks to improve consultee's problem-solving skills and knowledge base to ensure their future success (Bramlett \& Murphy, 1998). Thus, the consultant endeavors to effect behavior change in children through an indirect collaborative problem-solving process and additionally to empower the consultee with the essential skills to allow for independent problem solving in the future (Kratochwill, \& Callan-Stoiber, 2002).

According to Guli (2005) behavioral consultation (Bergan, \& Kratochwill, 1990) is the most widely used model in schools and has been effective as an indirect intervention delivery model. Behavioral consultation is a structured linear model that follows a specific sequence, utilizes protocols, measurements and interviews, that are objective and easy to understand and is operationalized through a four-stage problem solving process. As a result it has received the utmost clinical attention and empirical investigation. As described by Bergan and Kratochwill (1990) the behavioral consultation model involves four problem-solving stages and three structured interviews. 
The first stage is problem identification in which the consultant conducts a Problem Identification Interview (PII). The PII is focused on identifying and describing target behaviors of concern as well as identifying acceptable alternative behaviors. Other relevant general background information is also identified during this stage. The second stage is problem analysis in which the consultant conducts a Problem Analysis Interview (PAI) in which the consultant and consultee discuss the results from stage one and develop an acceptable plan. Next the consultee implements the plan and finally the consultant and consultee evaluate the plan.

Behavioral models tend to follow a hierarchical, prescriptive approach in which the consultant (considered the expert) unilaterally attempts to control the actions of others by operating in a directive, prescriptive, and sometimes coercive manner. The consultant engaging in this approach takes a lead role in all aspects and stages of the consultation process. For example, the consultant will identify the targets for intervention as well as the evidence-based practices to be used. The consultant will also train the consultee in the necessary procedures of the intervention and monitor the effectiveness and treatment integrity through ongoing feedback. It is obvious that the consultant in this model wields strong authority and influence over the design and implementation of interventions.

Several limitations have been associated with this approach. For one the "expert" instructs consultees in pre-developed strategies and expects strict adherence and accuracy in implementation. There is little flexibility for consultees in implementing interventions, little ownership in interventions, and little empowerment on the part of consultees. Limited input from important stakeholders such as teachers and parents also results in interventions that often lack social and cultural validity and are not always acceptable to consultees. As a result, the 
interventions are not sustainable, that is, they are not implemented with appropriate treatment fidelity and duration needed to be effective.

Kelleher et.al., (2007) suggest that an expert-driven model does have some advantages, namely that consultants ensure that clients receive empirically-based interventions as determined by the consultant and the consultation process in general may be more efficient to implement than a collaborative one.

Behavioral consultation has become a viable option as a service delivery model in schools due to the increasingly complex nature of students, the lack of empirically based interventions in classrooms, and research documenting its efficacy and efficiency. Behavioral consultation as an indirect system for delivering interventions has been verified by numerous studies as effective not only in decreasing problem behaviors, but also in increasing academic skills in children in both school and home settings. Moreover, according to Sheridan, Welch, and Orme (1996) it is also effective in changing consultee behavior. Consultees use the new skills and techniques they learn during behavioral consultation and increase their use of psychological services as well. Sheridan, Welch and Orme (1996) maintain that for general consultation studies completed between 1985 and 1995, 76\% resulted in positive changes for children, while studies specific to behavioral consultation $95 \%$ resulted in positive changes for children. In comparison only $60 \%$ and $38 \%$ respectively for mental health and other consultation models resulted in positive gains for children. In twenty-one behavioral outcome studies between 1985 and 1995 all but one utilized carefully controlled experimental or quasi-experimental designs (Macleod, Jones, Somers, \& Havey, 2001). Given that the methodological standards for the studies that involved behavioral consultation were significantly more rigorous than those in other types of 
consultation, it suggests that the behavioral consultation studies yield the most favorable results (Sheridan, Welch, \& Orme, 1996).

\section{Conjoint Behavioral Consultation}

Conjoint behavioral consultation $(\mathrm{CBC})$ is similar to behavioral consultation in that it is a structured indirect service delivery model that brings together individuals to address social, behavioral, and academic needs of children. However, one salient difference is that it focuses on uniting parents and teachers to work on behalf children (Sheridan \& Kratochwill, 1992). Conjoint behavioral consultation is a conceptual and procedural expansion of behavioral consultation in that it effectively combines the structured method of behavioral consultation that has been empirically validated with advances in ecological-systems theory (Sheridan, 1997). The integration of ecological-systems theory and behavioral theories allows users of CBC to address both systemic influences of the child such as home, school, and community and functional events such as antecedents, consequences, and settings. While the focus of behavioral consultation research and practice is based squarely in school settings, CBC seeks to build and strengthen relationships between home and school environments, facilitate collaborative partnerships, encourage parent engagement, and influence child behavior change (Sheridan \& Kratochwill, 2008).

The CBC stages are derived directly from the behavioral consultation model and are logically operationalized through structured interviews. The stages for CBC are: Conjoint Needs Identification Interview, Conjoint Needs Analysis Interview, Plan Implementation and Conjoint Plan Evaluation. The goals of CBC, according to Sheridan, Clarke, and Burt (2008), are to provide evidence-based interventions to students while at the same time engaging and including parents in the learning process. Additionally, and central to $\mathrm{CBC}$ model, is to build relationships 
across families and schools. Research has revealed that parent involvement and support improve academic achievement and may account for as much as $60 \%$ of the variance (Christenson \& Buerkle, 1999). Furthermore, when teachers and parents collaborate it is probable they will identify similarities and differences between settings and will plan for generalization (Sheridan \& Kratochwill, 1992).

In a review of research on a variety of parent consultation models, Guli (2005) found CBC to be the most efficacious of all the models included in the review and the CBC studies were also rated as being stronger in methodological rigor than the other studies. Guli (2005) also suggested that $\mathrm{CBC}$ is potentially an evidence-based model that produces important outcomes in academic, behavior, and social areas associated with school. A number of studies have documented positive outcomes related to behavior and anxiety (Wilkinson, 2005), completion of accurate homework (Galloway \& Sheridan, 1994), and development of social skills (Sheridan, Kratochwill, \& Elliot, 1990).

Multiple baselines across subjects design were used in several studies utilizing CBC for social skills deficits. Social initiation behaviors were the focus of a study by Sheridan, Kratochwill, and Elliott (1990) in which CBC and consultation with teachers only were compared as two treatment conditions. The four socially withdrawn children in the study had baseline social initiations of 1 initiation per week. All children received the same treatment which included setting goals, self-monitoring, and reinforcement. Children in the CBC condition increased social initiations in the home setting as well as the school setting while children in the teacher consultation condition increased initiations in the school settings only. Maintenance and generalization were also demonstrated in the $\mathrm{CBC}$ condition. In another study investigating $\mathrm{CBC}$ with children experiencing social skill deficits and ADHD, Sheridan (1998) added behavioral 
social skills training and reinforcement to CBC. The study focused on three boys ages 8-9 and occurred in cooperative play sessions in which seven social skills were targeted for training. All three subjects increased positive play behaviors and interactions that approached normal levels. In addition, teachers and parents rated the $\mathrm{CBC}$ procedures as acceptable.

In carefully controlled case studies, Galloway and Sheridan (1994) evaluated CBC with academically underachieving children who had difficulty completing homework assignments in a timely manner and with adequate accuracy. The researchers evaluated the efficacy of a typical intervention with one condition including a $\mathrm{CBC}$ component and one not including a $\mathrm{CBC}$ component using six primary grade students. The intervention included a note sent to the children's home as a reminder to parents of their responsibilities and to record daily performance. In addition, the note included possible reinforcers and methods for handling problems. In addition to case studies, an $\mathrm{AB}$ design with replications was used to assess the condition that included only the home note and the $\mathrm{CBC}$ condition. In both case studies and $\mathrm{AB}$ designs all students, regardless of condition, improved on all dependents measures, but larger and more stable gains were found in the CBC condition. The authors suggest the consultation component appeared to enhance the outcomes over what would be expected for students with a history of failure with traditional intervention strategies.

It appears that the initial focus of behavioral and conjoint behavioral consultation models was to simply provide professional services in a top down approach. That is, for the consultant to be the sole professional who identifies problems and develops remedial interventions focused on child deficiencies within an isolated system (Sheridan, Warnes, Cowan, Schemm, \& Clarke, 2004). Interventions developed in this manner have often led to a lack of acceptance among consultees. In contrast, a partnership model is based on the assumption that all stakeholders 
should have equal say and participation in identifying children's needs and establishing social supports in order to enhance outcomes (Sheridan Warnes, Cowan, Schemm, \& Clarke, 2004). The partnership model infuses partnership and joint responsibilities in every stage of the consultation process and promotes strength, skill and capacity building within individuals, families, and systems. As a result, there is improved communication between family and school and a real sense of empowerment for important stakeholders. The CBC model has the potential to encourage and create active partnerships.

One investigation examined the degree that a partnership orientation in $\mathrm{CBC}$ would predict case outcomes and whether the structured empirically supported procedures in the CBC process can remain intact, that is, be delivered with integrity when delivered within a partnership approach (Garbacz, Woods, Swanger-Gagne, Taylor, \& Black, 2008). In this study, which included 20 child participants, 19 consultants, 20 parents, and 19 teachers, the authors defined partnership orientation as how effective the consultant was in demonstrating a partnership orientation throughout the $\mathrm{CBC}$ interviews. Partnership orientation also served as a predictor variable for case outcomes. Both teachers and parents rated outcome variables of acceptability, satisfaction, perceptions of effectiveness, and child performance across home and school settings. Measures were secured through various rating scales, evaluation forms, and checklists. The partnership orientation measure (POM), which is a seven-item Likert Scale, was developed to assess the degree to which consultants demonstrated a partnership orientation. The Behavior Intervention Rating Scale (BIRS-R) was used to measure acceptability and effectiveness and $\mathrm{CBC}$ objective checklists were designed around the structured interview forms and used to measure process integrity across cases and interviews. 
This was an initial study in which a partnership orientation was embedded within CBC. Several significant findings were revealed including a linear relationship between partnership orientation and teacher acceptability as well as between partnership orientation and teacher satisfaction. What this revealed, according to the authors, is that embedding a partnership process within $\mathrm{CBC}$ is predictive of both teacher acceptability and teacher satisfaction. Including a partnership model in CBC was not, however, predictive of either parent acceptability or satisfaction. Researchers theorized that for parents being included in the problem-solving and decision-making processes was more important than a feeling of a partnership. With respect to the researchers' hypothesis that partnership orientation may impact negatively the CBC process integrity, this was not the case. The study did not reveal a significant correlation between CBC integrity and partnership, that is, the $\mathrm{CBC}$ process can indeed be completed with integrity while at the same time emphasizing a partnership orientation. Lastly, the partnership orientation did not significantly impact child outcomes.

\section{School Counseling}

In schools that emphasize collaborative environments as a structure to assist students with diverse needs, counselors are equipped to provide guidance in development of teams and relationships. School counselors have made significant contributions to a collaborative view of consultation. For example, in the school consultation literature counseling was defined as a shared decision making process analogous to collaboration (Brown, Wyne, Blackburn, \& Powell, 1979). Critical elements of collaborative teams included working toward common goals, the belief that each member has unique expertise whose input is valued and the accountability of each member (West \& Idol, 1993). The collaborative model of school consultation or 
collaborative consultation emphasized not only the interactive nature of counselling, but also the processes of mutuality, reciprocity, and diversity of expertise (West \& Idol, 1993).

School counselors have also used collaborative consultation to bring together families and others in the community to help at-risk youths. In this model, counselors use collaborative consultation to actively involve parents, educators, and youths in the problem solving process as equals and as experts (Nevin, Thousand, Paolucci-Whitcomb, \& Villa, 1998). The collaborative model used by school counselors highlights the aspects of shared responsibility and the interdependence of group members, all of which moved away from traditional mental health and behavioral consultation models.

\section{Participatory Intervention Models}

An alternative approach to behavioral models is the participatory intervention model (PIM) based upon principles of action research (Greenwood, Whyte, \& Harkavy, 1993; Nastasi, 1998). The defining feature of this model is key stakeholders or those who have vested interests in the focus of the intervention being fully involved in the process. When applied to schools stakeholders may include teachers, parents, paraeducators, and school administrators (Nastasi, Varjas, Schensul, Silva, \& Ratnayake, 2000). Conceptually, the PIM is a partnership-based model that promotes the formulation and continual development of non-hierarchical and collaborative relations between consultants (interventionists) and stakeholders as well as among schools, community partners, and research teams (Power, Dowrick, Ginsburg-Block, \& Manz, 2004). The model is iterative and does not proceed in a linear fashion. PIM is designed to be conducted in real-life settings and is thus highly context-bound which is consistent with both naturalistic methods of inquiry and ecological approaches to research and intervention. It is highly applicable to efficiency research that occurs in naturalistic settings. 
Participatory models have been used as a vehicle for implementing research-based interventions that integrate theory, research, and practice. The purpose is to empower and to give ownership to stakeholders so that they are more willing to accept and implement research-based interventions. It seeks to empower participants by engaging in collaboration and partnership in all steps of the consultation process. Collaboration within PIM models is viewed as a dynamic entity that varies throughout the process. For example, while the collaborative approach is emphasized, it is just as important for the consultant to sometimes take a leadership role especially during initial phases when knowledge acquisition and skill development are important. Once stakeholders achieve necessary knowledge and expertise they move toward equal status. The development of a sense of partnership that is cultivated through involvement in designing and implementing interventions is crucial in participatory models and forms the bases for ownership and empowerment that precedes and generates acceptance of mutually developed interventions.

The three phases of PIM are Participatory generation, natural adaptation, and essential changes. The participatory generation phase is comparable to intervention development in behavioral models in which goals are set and interventions developed. Formative evaluation is used to identify/assess individual variables (competencies and behaviors, cultural practices, and resources) as well as cultural variables to identify strategies and culture specific goals (Nastasi et al. 2000). Natural adaptation is the implementation phase, but instead of emphasizing strict adherence to planned interventions, participatory models advocate continual modifications and adaptations to interventions based on individual needs and the natural context. The process of natural adaptation creates two advantages. One, because interventions are changing it is necessary to monitor intervention integrity (which will be discussed in-depth below) and as a 
result elements critical to intervention success can be discerned as well as noncritical elements. Two, because natural adaptation requires reiterations to the participatory generation phase it strengthens the goals of acceptability and sustainability.

The final component, essential changes, documents how effective the intervention was or what the impact was on outcomes targeted. Unlike traditional models that focus on transfer of skills to multiple settings, participatory models also assess whether change efforts persist or are sustained. All three phases are designed to be continually revisited (iteration) and refined in order to advance the goals of intervention acceptability, sustainability, integrity, and effectiveness (Nastasi, et. al., 2000).

Case illustrations and studies have applied the principles of participatory intervention in an effort to establish partnership-based programs. In one case example researchers used a community partnership model based upon principles of PIM to prepare and support community residents to be trained as community paraeducators (Power, Ginsburgh, \& Dowrick, 2010). The process began with the co-construction of roles and responsibilities with regard to designing, implementing and evaluating a school-based intervention for remediating reading difficulties. The researchers presented an instructional protocol based on empirically supported reading strategies. The community paraeducators used their knowledge of the community to collaborate with researchers in developing culturally relevant materials. In the next phase of supervising the paraeducators, researchers initially held meetings common to university standards, which included preplanned agendas, predetermined time lines and kept personal communications to a minimum. What emerged, however, was a supportive supervision structure that allowed for a more flexible agenda and permitted professional discussion along with personal 
communications. The net result was a strengthening of the social network among community paraeducators.

Collaborative planning with school personnel and community paraeducators was also central to the development of a mutually acceptable evaluation plan. The researchers report that community paraeducators participated in every aspect of program evaluation and because of their knowledge of both school and community were able to provide invaluable insights. Finally, community paraeducators participated in the development of an intervention integrity evaluation system. Integrity monitoring usually involves some type of observation of intervention sessions and the completion of a checklist to examine adherence to procedures. This approach precluded the possibility that community paraeducators might believe that researchers doubted their ability to deliver proper tutoring.

A different study focused on improving literacy skills among low-income urban students in elementary grades (Power, Dowrick, Ginsburg-Block, \& Manz, 2004). Within a PIM context, researchers collaborated with community partners to develop evidence-based reading interventions that were appropriate and responsive to the cultural needs of students. Two first grade students and two community partners participated in the study. Outcome measures for students were phonemic awareness and passage reading, while outcome measures for community partner tutors were intervention integrity. Student progress was evaluated by an A/B design that compared baseline and intervention phases and a Reliable Change Index was calculated as well. An integrity checklist that was completed by community partners and a school psychologist evaluated intervention integrity.

Results for one student showed an increase of .54 words per day and 3.78 per week. RCI was also significant with a calculation of 2.38 which is greater than the 1.9 cutoff at the .05 level. 
Student two increased .19 words per day and 1.33 per week with an RCI of 1.27 , which was not significant at the .05 level. While not significant, the authors suggest that an improvement of one word per week is considered educationally significant. The average rating on an eleven-item checklist for intervention integrity was 5.5 on a scale of 6 for both tutors. Both tutors also stated that the training procedures were helpful. The inter-rater agreement for the two tutors was .93 and $100 \%$. Lastly, the authors suggest that mutual exchange of information and ongoing opportunities for collaboration are essential for success of the program.

\section{Collaboration in consultation}

Virtually all scholars, regardless of theoretical perspective, believe that consultation must be collaborative if it is going to be properly conducted (e.g., Noell \& Witt, 1999). However, defining collaboration in measureable terms is a difficult task and one that has not been fully realized. Many efforts to define collaboration include concepts such as nonhierarchical relationships, shared responsibilities, and the ability of the consultee to reject what the consultant has suggested. Frequently, collaboration is operationally defined in terms of relational communications such as controlling the conversation either by the consultant or consultee or concepts such as dominance and domineeringness (Erchul et al., 2009). Collaboration is usually conceptualized as a dichotomy between collaborative nonhierarchical and expert hierarchical approaches.

The role the consultant takes when working with consultees depends on the approach to which the consultant subscribes. For example, the consultant could take either a directive or collaborative approach when working with consultees. A directive approach to consultation is based on the "expert" theoretical perspective in which the consultant unilaterally dictated the course of actions for the consultee to follow and one-way communication is the norm. Gutlin 
(1999) called this model directive or prescriptive because the consultant, usually an outsider, would diagnose a problem and write prescriptive plans to be carried out by consultees. In this model the consultant does not seek input from consultees in any problem solving endeavors nor is the consultant involved in implementing the plan. The traditional expert model is hierarchical and the consultant is directive and prescriptive.

On the other hand, a collaborative model is described as one in which the consultant seeks to build partnerships and to actively include consultees as equal partners in the processes of intervention design, implementation, and evaluation (Wickstrom et al., 1998; Gutkin, 1999) The consultant seeks input and participation from consultees and engages them in joint problem solving and decision making while taking on a more facilitative role.

Gutkin (1999) proposes conceptualizing collaboration as a continuous variable in which directive and collaborative models lie on a continuum with the directive approach and no participation on one end and full collaboration and participation as the ideal on the other. Collaboration, however, does not prohibit using directive strategies by the consultant and it may even be that the two extremes constitute a false dichotomy.

In traditional models of consultation in schools, the consultant was considered the "expert" who delivered (directed) services through a consultee to solve problems in the classroom. Gradually, however, the concept of collaboration in which all members of a team were considered to have expertise in some area began to emerge and became incorporated into all models of consultation including behavioral consultation. It was apparent that one person could not possess enough expertise to meet the diverse needs of all learners. Collaboration became the norm and was considered to be a foundational element of consultation. However, 
there was no agreed upon definition of collaboration and many different definitions and implicit views permeated the literature; collaboration in consultation quickly became controversial.

According to Dinkmeyer and Carlson (1973) the expert model had been ineffective for several reasons. The first reason was a direct result of a lack of collaboration. For example, consultees had no input in any phases of the consultation process. Most notably, consultees were not involved in the process of developing interventions and as a result, felt no connection with the intervention, did not find it acceptable and were more than likely not interested in implementing it. Moreover, interventions developed this way were neither socially or ecologically valid nor culturally responsive. Another reason for consultees resisting expert consultants' directives was the hierarchical nature of the approach. Consultees were put in a subordinate position with little input and little value placed on their opinions. They had no ownership of interventions developed in this manner. Finally, the consultants' role of providing ongoing feedback but not being directly involved in implementing the intervention or subsequent changes lead to more resistance among consultees.

Gutkin (1999) further suggested that the expert model was ineffective because psychologists and other "expert" consultants realized that they didn't have all the answers and others had unique knowledge and perspectives to contribute. In addition, it became clear that consultees responsible for implementing interventions were more likely to do so if they had input into the process. Collaboration began to be viewed as a necessary and essential component and as a vehicle to share expertise and to provide the best services possible (Gutkin \& Curtis, 1982). The accepted view was that collaboration enhanced the consultative process by increasing the probability that plans would be implemented and that consultation would be used more frequently. Research suggested that in order for consultation to be effective it must be 
collaborative and that teachers actually preferred a collaborative approach (Pryzwansky, 1983). Collaboration originated because it was clear that consultees had to accept and act on the information provided by consultants if clients were going to benefit. All of this has led researchers to examine collaboration more closely in an attempt to determine which behaviors constitute collaboration, how they could be measured and most importantly how they affected learner outcomes.

Defining collaboration or even agreeing on the dimensions that should be measured, however, was a difficult task and one on which there was little agreement. As a result, judging whether a specific instance of consultation is collaborative depended on one's view of what constitutes collaboration. For example, if a consultant actively directs the problem-solving process she could be acting collaboratively or non-collaboratively depending on one's theoretical perspective. According to Gutkin (1999) joint decision-making and input from consultees is the hallmark of collaboration so if someone were acting unilaterally it would not be viewed as collaborative. On the other hand, Caplan (1970) views collaboration in terms of joint responsibility and joint accountability for client outcomes and as such the consultant must be certain that students are getting services that constitute best practice in their area of expertise. According to this view of collaboration actively directing the problem-solving process is indeed collaborative. The inconsistency in defining collaboration and determining dimensions on which collaboration should be measured is a problem that has been acknowledged by most researchers (e.g., Erchul, 1999; Gutkin, 1999).

The assumption that collaboration in school-based consultation was the norm was seriously challenged in the 1980s and culminated in a paper by Witt (1990a) in which he stated that not only was there a paucity of empirical evidence in support of a collaborative approach, 
but, the opposite may in fact be true. Several studies seemed to lend support to a directive approach to consultation. For example, Erchul and Chewning, (1990) compared how often teachers were successful in controlling conversations versus how often the consultant successfully controlled the conversation and found that teachers preferred a more directive approach .

Gutkin (1999) argued that collaboration should be understood simply as the dictionary defines it, "to work jointly with others...to cooperate". In responding to Witt, in his extensive review of the literature, Gutkin (1999) asserted that the opposite of collaboration is not directive, but instead the opposite of collaboration is coercion and the opposite of directive is nondirective. He defines collaboration as consultants making joint decision with consultees with each providing input and exerting leadership when appropriate. Coercion was defined as consultants engaging in unilateral decision making with the expectation that consultees will follow their lead whether they agree or not. Directive was defined as consultants influencing the consultation problem solving process by explicitly employing their expertise while nondirective was when a consultant does not overtly express their professional expertise during the process. He concluded by asserting that consultants can concurrently be collaborative and directive at while maintaining their expertise as well as their collaborative relationships. Gutkin (1999) concluded that by using these definitions, consultation can take any of the following forms: collaborative and directive; collaborative and nondirective; coercive and directive; and coercive and nondirective.

\section{Theoretical Constructs Conceptual Definitions and Views of Collaboration}

Schulte and Osborne (2003) agreed that unanimity on a definition of collaboration was lacking and that the construct of collaboration in consultation has generated more debate than any other construct. They recognize that collaboration is complex and multidimensional and researchers 
and practitioners alike tend to hold implicit views of what collaboration is. They also are cognizant that researchers differ on the dimensions used to judge whether an instance of consultation is collaborative and disagree on how to operationalize and measure different dimensions of collaboration. Schulte and Osborne (2003) argue however, before an operational definition of collaboration is developed building a consensus conceptually concerning the meaning of collaboration is of utmost importance. As a result, Schulte and Osborne (2003) suggested that collaboration could fall into one of six categories depending on which behavioral indicators were used to determine a collaborative or noncollaborative interaction. Following is a brief description of each category.

\section{Equal but Different}

The equal but different view of collaboration asserts that consultees will implement interventions with a greater degree of integrity because of the complimentary roles that each member assumes in the problem solving process at all levels. That is, the consultant and consultees work jointly in identifying problems, analyzing problems and developing interventions. The consultant at times will guide the process and may even exert influence to facilitate change, but there is no joint responsibility for decision-making, all decisions are the responsibility of consultees. The consultant is not involved in the delivery of the intervention.

Carrington, Cleveland, \& Ketterman, (1978) describe the consultant as a process expert who gives advice about a how a process works but leaves the application of the process to the consultee. According to Kurpius (1977) Consultants are not better or more expert, they merely have different roles. This model was the first to use the expression collaborative consultation. 
The assumptions about change are the same as in the equal but different model such as increased implementation of interventions because of consultee involvement in the process, but the models differ in that there is no superior or subordinate role in the peer facilitator model. The consultant is truly a peer and only attempts to induce change indirectly, which the consultee is free to reject.

In this view providing technical assistance is not the role of the consultant. The consultant doesn't bring special knowledge about a topic, but instead attempts to develop a relationship with the consultee. The consultant acts in a nondirective mode and follows the lead of the consultee and the consultee is given complete autonomy. As a result, guiding the process as in the equal but different model or providing direct advice would lessen the value of the collaboration and deter from the goal of consultee autonomy. In fact, Dinkmeyer and Carlson, (1973) assert, "the relationship is truly collaborative and any attempt to exert authority or impose his judgments may produce resistance and slow the change process" (p, 88). Peer facilitator is a style of interaction that promotes support and encouragement; it is essentially about the quality of the interaction (Caplan, 1970).

\section{Unique Service Delivery Model}

Other early researchers (e.g., Caplan, 1970, 1993; Pryzwansky, 1977) used collaboration to refer to a unique service model, which was basically different than consultation. The assumptions about change within this model come from the fact that the consultant and consultee share responsibilities for outcomes. This means that the consultant can override the consultee when it comes to what is best for the client. If the consultant has expertise in evidence based educational practices then those practices need to be implemented regardless of whether the consultee is in agreement. 
The major theoretical difference between this model and the two previously described models is that in this model the consultant's direct involvement in implementing the plan is thought to improve the integrity with which the plan is implemented. The direct involvement takes the form of the consultant being available to assist the consultee in implementing the plan, to provide continuous reinforcement and follow-ups and to assist in subsequent changes of the plan (Pryzwansky, 1983).

\section{Consultant-structured Consultant Participation}

Generally speaking, this model is similar in nature to the expert model in both structure and consultant role. For example, the consultant directs or controls the process in order to drive plan development in ways that are consistent with her area of expertise, but at the same time the consultant seeks input from the consultee on some aspects of the process. Originally, the consultant only had to seek input during the development of the intervention for it to be considered collaborative (Wenger, 1979). The assumption was that the consultee is less likely to reject the plan because she was directly involved in the process.

Bergan's (1977) initial behavioral consultation model is similar to this model. The main difference is that for Bergan's model to be considered collaborative the consultant seeks input from the consultee in both formulating the plan for intervention and defining the problem, however all other steps in the process fall within the purview of the expert consultant. In Bergan's and the consultant-structured model the consultant is not involved in implementing the plan. That is the sole responsibility of the consultee.

\section{Shared Assent}

This model is unique for several reasons. First, there is a mediator between the consultant and consultees. The consultant works directly with a mediator, usually a teacher in an 
educational setting, who in turn works with paraprofessionals who deliver interventions. The consultant is concerned with modifying the mediator's behavior usually through behavioral means of shaping and stimulus control. The consultant is thought to have a certain knowledge or skill to be passed on to the mediator. The mediator's input may be sought, but generally there is not much active involvement on the part of the mediator.

Second, the theory that supports this view of collaboration suggests that consultation is collaborative only when both the consultant and consultee define and agree on what the relationship will be, that is roles are mutually defined and may change with each phase and particular situation. The assumptions about change in this model are based upon the idea that consultees are not just given input, but actually have a choice of how to participate and about what is considered collaborative. The model theoretically utilizes and considers the strengths and weaknesses of all participants. Because who assumes what role in this model is mutually agreed upon and there is no predetermined delineation of roles any arrangement, combination or blend of roles can be considered collaborative. So one party may assume complete control for decision making in any phase in the process and it would be considered collaborative if mutually agreed upon by all participants. Degree of directiveness and nature of hierarchy is not an issue so long as it is an agreed upon structure.

Another perspective of this model was offered in which more emphasis was placed on collaboration between the consultant and mediator (Idol, Nevin, \& Paolucci-Whitcomb, 1995). These researchers were concerned with the constructs of parity and equality among multiple collaborators and suggested that the consultant's and mediator's skills should be blended and that each one had a unique knowledge base and expertise that could be used depending on the situation. 


\section{Equal valuelequal power}

This view of collaboration is based on parity and equality where all participants are equal and have valuable input. Proponents of this model (Friend \& Cook, 2010) define collaboration as a style or way of interacting that can be applied to any number of disciplines and educational contexts. Mutual respect and trust and the willingness of participants to share their knowledge are the hallmarks of this model. Additionally, each member shares responsibility for outcomes and decision-making, which contributes to a sense of ownership among members. A member's particular area of expertise does not entitle her to assume a leadership role in this view of collaboration and any attempt to direct the problem solving process is viewed as noncollaborative.

\section{Treatment Integrity}

Treatment integrity, defined as the "degree to which intervention steps, procedures or programs are implemented as planned" (Gresham, Gansle, Noell, Cohen, \& Rosenblum, 1993, page 345), has also been referred to in various literatures as treatment fidelity, intervention implementation integrity, program integrity or procedural integrity as it is referred to in applied behavior analysis literature. Historically, it refers to the accuracy and consistency with which an intervention is applied. It is critical to the ultimate goal of intervention efficacy research conducted in highly controlled contexts, which is to demonstrate unequivocally that change in a dependent variable is the result of systematic change in an independent variable and not to extraneous variables. It is also critical to indirect service delivery models which are only effective if teachers, instructional aides or parents implement interventions as planned (SwangerGagne' et al., 2009). 
The importance of monitoring treatment integrity has long been acknowledged in both intervention research and practice (Shadish, Cook, \& Campbell. 2002). It was first discussed in the applied behavioral analysis literature where it was essential to define independent variables precisely through operational definitions so that measures of implementation accuracy could be carried out (Petersen, Homer, \& Wonderlich, 1982). In this early notion of treatment integrity, researchers specified a level of occurrence of an independent variable and compared it to the actual occurrence to form a simple ratio from which to compute percent accuracy. This is in line with earlier accuracy criterion that reflects how well the match is between a predetermined standard and observations scored by an observer (Kazdin, 1982). This measurement strategy has been labeled "therapist adherence" and continues to be an important measure of one component of treatment integrity. Recent conceptualizations of treatment integrity, however, view it as a complex multidimensional construct that includes measures of quantitative as well as qualitative dimensions - see multidimensional section below.

Measuring treatment integrity contributes to and promotes experimental validity (Cook \& Stanley, 1979), helps to account for threats to experiments, and permits researchers to draw valid and reasonable conclusions and link programs and outcomes. Internal validity, for example, controls for extraneous variables and demonstrates that the treatment accounted for changes in the behavior. Thus confidence in internal validity may be compromised if no data about treatment integrity is available and significant changes in behavior occur because the intervention may or may not have been applied as planned and extraneous variables may have caused the change. Likewise, if changes in behavior are not apparent and treatment integrity measures are not collected it is challenging to distinguish between a basically ineffective treatment and a treatment that may be effective but was implemented poorly (Gresham, 1989). 
Monitoring treatment integrity helps to expose poorly conceptualized and poorly designed interventions that have been implemented correctly. In addition, it assists in differentiating between intervention components that may or may not be critical for success (Perepletchikova \& Kazdin (2005). Treatment integrity also provides relevant data for external validity and construct validity both of which contribute to overall experimental validity.

Several factors have been identified as being related to treatment integrity and that contribute to making it difficult to measure (Gresham, 1989). The first is the complexity of the treatment, which is particularly problematic for indirect service models. Generally speaking more complex treatments will result in lower measures of treatment integrity (Mortenson \& Will, 1998). The second factor is the time it takes to implement the treatment, which is usually related to the complexity. For example, more complex interventions require more time to implement and the greater the possibility of a lapse of treatment integrity - often referred to as therapist drift. Third, interventions requiring materials and resources not usually found in typical classrooms most likely will result in decreased adherence to intervention protocols. In contrast, Gresham et al. (2000) point out that treatments that are judged to be more effective and acceptable by those responsible for implementing them are usually implemented with a higher degree of integrity. Indirect service delivery models further complicate the process of measuring treatment integrity because: 1) it potentially involves measuring both consultant behavior and consultee behavior and 2) given the demands of the settings (additional time and resources demanded of teachers) and treatment complexities delivery of behavioral treatments through indirect formats may be compromised as well as at risk for inaccuracies (McIntyre, Gresham, DiGennaro, \& Reed, 2007). In discussing the difficulty of promoting and measuring treatment integrity within indirect service models, Noell (2008) highlighted a distinction between what he termed 
consultation procedural integrity and treatment plan implementation. He suggests that it is just as important to measure how well consultants adhere to particular models as it is to measure how well consultees adhere to treatment procedures. He recommends that for both levels of treatment integrity basic questions must be asked about whether the treatment was delivered as suggested and how accurately the treatment was delivered. For example, a consultant who suggests that she followed a particular theory of consultation should provide evidence of this as should an interventionist who suggests that she provided a particular intervention.

Given the important role of monitoring treatment integrity which is tied to intervention outcomes and is critical to interpreting findings (Noell, Gansle, \& Gresahm, 2002) it is unfortunate that it has not been consistently addressed in research or practice and has lagged behind conceptually as well. In an analysis that examined the status of school-based intervention studies with respect to monitoring treatment integrity from 1980 to 1990 , it was discovered that only $14 \%$ of studies in their review included data for treatment integrity while $10 \%$ discussed treatment integrity, but did not collect data (Gresham et al. 1993). In a follow-up, which focused on research in learning disabilities from 1995 to 2000, Gresham et al. (2000) reviewed research articles in three major learning disability journals and found that only $18.5 \%$ measured integrity. The authors commented that not including integrity data makes it difficult to state unequivocally which treatments are effective or ineffective. In addition, a national survey of school psychologists (Cochrane \& Laux, 2008) revealed that only $11.3 \%$ of respondents always assess intervention integrity even though 56.2\% acknowledged its importance. Finally, in research on conjoint behavioral consultation, systematic methods for assessing treatment integrity have not been on par with CBC efficacy research and in fact have not occurred until recently (SwangerGagne' et al., 2009). 
Traditionally, researchers have viewed treatment integrity in terms of therapist adherence to intervention procedures (Gresham et el., 1993) or how well the program implementer followed the steps of an intervention as expressed in a training manual. An advantage of this approach was that procedures contained within treatment manuals were usually the result of extensive development and based on theories and practices that were validated and empirically supported. In addition, treatment integrity viewed as adhering to preplanned intervention procedures allowed for ease of monitoring as checklists could be produced to mirror the intervention steps and then used to observe intervention sessions. This manner of monitoring integrity is reflective of a hierarchical model that is a top down approach suggesting a basic inequality between researchers and practitioners.

Using a hierarchical framework allowed researchers to tightly control and quantify the process of monitoring treatment integrity. Researchers were able to ensure treatment integrity by providing intensive training and supervision to interventionists and by using standardized intervention procedures, all of which made monitoring and measuring integrity fairly simple. For example, the two most important things to consider when measuring adherence to treatment protocols are the degree to which the interventionist followed the procedures or protocol and the degree of exposure measured as the number, length, and frequency of intervention sessions. Both measures are easily quantifiable. Additionally the precise delineation of intervention steps and program components allowed researchers to clearly differentiate between experimental interventions (i.e., contains specified components) and controls, which in turn provided clear guidelines for further replications.

Clearly, a hierarchical approach to monitoring treatment integrity (i.e., "therapist adherence" to treatment protocols) has many advantages especially when research is conducted 
in controlled contexts. However, several limitations must be noted. This approach does not include stakeholders in either intervention planning or treatment integrity monitoring. As a result, it is not very responsive to their needs, beliefs, and values and thus may result in inadequate levels of social validity (Kelleher et al., 2008). In addition, hierarchical approaches are not a good fit in research that occurs in classrooms and other natural settings that are not under the tight control of researchers, sometimes referred to as effectiveness research. Conducting this type of research requires a level of flexibility not normally found in tightly controlled settings.

In one study designed to use a hierarchical approach to monitor treatment adherence, paraprofessionals/aides in charge of student supervision during lunch were recruited to teach kindergarten and first grade students about the necessity of eating fruits and vegetables and their relationship to good health (Power, Blom-Hoffman, Clarke, \& Manz, 2005). The program consisted of a classroom component to teach students about eating healthy and a lunchtime component to assist children in eating more fruits and vegetables. Researchers used a variety of procedures including modeling, direction instruction, and in-vivo coaching to teach aides the following procedures to use during lunch; 1) ask children where the fruits and vegetables are located, 2) provide praise to children when eating fruits and vegetables, and 3) provide stickers to children contingent on fruit and vegetable consumption. Twenty-one percent of the procedures were monitored through direct observations to verify that procedures were being adhered to. Data revealed excessive variability with respect to intervention procedures during lunchtime. For example, while aides were consistent in asking students where the fruits and vegetables were, they infrequently praised them for eating them and rarely gave students stickers for eating fruits and vegetables. During a focus group with aides to determine what may have caused the 
variability, researchers discovered that the procedures were difficult to remember during the usually hectic lunchtime. As a result, the students themselves usually volunteered to identify fruits and vegetables and had to remind the aides to pass out stickers. The researchers concluded that they could have made adjustments to the intervention protocols and improved adherence to treatment procedures by engaging in regular collaboration with the aides focused on the challenges encountered during implementation and the identification of mutually agreeable strategies to monitor integrity.

\section{Multidimensional Construct}

Limiting the definition of treatment integrity to the degree of adherence to preplanned intervention procedures is somewhat simplistic and does not capture the essence of the complexity of the construct. Many researchers (Jones, Clarke, \& Power, 2008; Noell, 2008) have discussed the complexity and multidimensional nature of treatment integrity and have suggested conceptual models that consist of numerous components or dimensions. Empirical support is emerging (Dusenbury et al., 2003; Durlack \& Dupree, 2008) that supports the multidimensional nature of treatment integrity and in particular supports dimensions proposed by Dane and Schneider (1998).

The Dane and Schneider (1998) model consists of five dimensions of treatment integrity that they classify as either measures of quantity of delivery or quality of implementation. The quantitative components relate to content issues such as how much of the intended program was covered or how much of the content was implemented and have generally been measured via direct observations or self-reports utilizing checklists. These quantity dimensions include adherence to program objectives and exposure to intervention procedures or how many and how frequently intervention was implemented in short, the amount of provided service received by 
the participant. Program differentiation is another quantity dimension discussed by Dane and Schneider (1998) and refers to differences between a "business as usual" approach and interventions. As mentioned above, program differentiation informs researchers about components of interventions and assists in determining which components work and which do not work. In essence, it is an effective approach to separating intervention components and determining the effectiveness of each treatment component. In addition, it clearly distinguishes experimental interventions that incorporate best practices from controls making replications more probable.

The qualitative dimensions in the Dane and Schneider (1998) model relate to process issues or how well the intervention was implemented. Quality of delivery is one dimension and includes qualitative aspects of intervention such as the effectiveness of the interventionist, the enthusiasm displayed during delivery and the level of preparedness of the interventionist, in short, the manner in which the service was provided Another qualitative dimension proposed by Dane and Schneider (1998) is participant responsiveness, which they defined as the degree of engagement of the participant in the intervention. This added dimension suggests that a program is not fully implemented until both the proper amount is delivered (dose delivered) and received (dose received). Therefore, it is critical to evaluate what is actually implemented, the manner in which it is implemented and the engagement level of participants in the process. These issues will be discussed at length in the section on measurement issues.

Full engagement in the intervention phase (Hagernoser-Sanetti, et. al 2011) is another potential dimension of treatment integrity. This potential was demonstrated in a study that found that interventionists reports of adherence were quite predictable suggesting that measures of adherence were not a sensitive enough measure and did not or differentiate integrity well 
(Swanger-Gagne et al., 2007). A more sensitive measure may be one in which interventionist's self-monitor adherence and document completion of steps on forms to be submitted to consultants for review. In other words, interventionists are fully engaged in the process.

While qualitative dimensions of treatment integrity have been expounded upon both theoretically and conceptually, scientific studies designed to develop and implement systems to monitor and measure qualitative dimensions have not been undertaken until recently. In one study researchers developed and piloted a method of evaluating treatment integrity within the context of preventing aggression in classrooms that targeted the degree to which key program and intervention content was implemented, how well they were implemented (process integrity) and how well participants were actively involved in intervention (i.e., student behavior, interest, enthusiasm, and level of distractibility) (Gullan, Feinberg, Freedman, \& Leff, 2009). This was the first attempt to develop a system that evaluated the degree, to which a program was implemented, the quality integrity components of the program and how participants responded, and participant responsiveness.

In order to respond to the unique needs of the local community a partnership-based approach was used to include community stakeholders and give them input with respect to both content of the intervention and the integrity system. The researchers identified four content areas from the literature to include in the integrity monitoring system and jointly identified (researchers and community partners), defined, and refined six implementation process variables. The system was further refined to include ten process variables instead of the initial six. One hypothesis of the study was that a higher level of process integrity would result in higher levels of improvement on dependent measures. The results did not support this hypothesis instead finding just the opposite (Leff, Powers, \& Mauz 2004). 
In this study several significant features and heuristics can be gleaned. It was the first to utilize a partnership approach in developing an intervention monitoring system based on expanded definitions of treatment integrity. It also demonstrated how empirically based program components can be combined with unique needs of a community to develop a culturally sensitive integrity monitoring system. It also laid the foundation for adapting manual-based interventions to real-world practice.

\section{Measurement Issues and Procedures}

Treatment integrity measures within the context of consultation give both researchers and practitioners the ability to infer functional relations between interventions implemented by consultees and consultation outcomes. The contextual realities of consultation research and the delivery of interventions in naturalistic or applied settings, however, create several unique problems when attempting to measure treatment integrity. For example, in addition to measuring the integrity of treatment plan implementation on the part of the consultee, it is also necessary to measure procedural integrity of the consultation process itself which includes the amount of consultation process objectives the consultant met (Noell, 2008). It is conceptualized as a twotier intervention with tier one concerned about the consultation process integrity and tier two the integrity of the program plan (Sheridan et al., 2009). Directly related to the two-tier intervention is the additional difficulty of defining or specifying independent and dependent variables in consultation. Consultation procedural integrity is unambiguously an independent variable and contributes to the internal validity of the study. On the other hand, treatment plan implementation can be conceptualized as a dependent, independent, or mediating variable. As a dependent variable, outcome measures relate to whether the intervention was implemented as planned and developed in the consultation process. As an independent variable, outcome measures relate to 
whether plan implementation lead to changes in child behavior. Finally, as a mediating variable, outcome measures relate to the degree to which plan implementation accounts for the relation between consultation (independent variable) and child outcomes.

Several other issues with the contextual realities of consultation also contribute to the complexity of the measuring treatment integrity. One is the inescapable reality that in consultation research interventions and to a large part measured effects are controlled by a consultee, which at the very least complicates the researcher's ability to measure integrity with specificity. Another issue, which may be directly related to indirect services, is the degree to which interventions vary from originally planned or vary from core aspects of treatment. Unplanned variations in interventions may create substantial threats to internal validity and make conclusions regarding change in dependent variables or regarding which intervention components were responsible for change difficult. Planned variations developed in a partnershipbased model, however, are considered enhancements to treatment integrity and may increase adherence and quality of intervention. This is discussed below. Finally, how to measure qualitative elements of intervention is problematic as no standardized agreed upon methods for measuring integrity in consultation have been developed (Sheridan, 2007). These issues may help account for the fact that treatment integrity and outcomes are examined in only $20 \%$ of consultation studies (Hahermoser, Sanetti, \& Kratochwill, 2008).

\section{Self-Report}

In consultation research, adherence to intervention plans is the most common form of treatment integrity measured; however, there are only a few methods available to assess adherence. These include: (a) self-report, (b) direct observations, and (c) permanent products. Self-report is the most common form for measuring treatment integrity. In self-report 
measurements a checklist specific to intervention components is completed by the individual responsible for implementing treatment. Thus, the measurement typically an estimates the level of adherence or completion of intervention procedures and is usually computed as the percent of steps completed. While self-reports are easy to use and work well in consultation, they are not always a reliable measure because consultees oftentimes over estimate their level of integrity (Sanetti \& Kratochwill, 2008).

\section{Permanent Products}

Some intervention components are designed to result in permanent products, which include tangible evidence such as charts, tokens or daily progress reports that can be used to assess treatment integrity. Permanent products can be completed daily by teachers or paraprofessionals and are a simple and less intrusive way to measure integrity because they are completed or produced as a natural part of intervention, without adding more work or responsibility for the interventionist. According to Sanetti and Kratochwill (2008) permanent products generate minimal reactivity in the classroom and gives researchers to ability sample multiple occasions of an intervention. A major advantage is that each permanent product produced corresponds with a particular intervention component. For example, if a treatment step specifies a tangible reward for a particular behavior, then the accumulation of rewards would serve as permanent products and would correspond to that step of the intervention. On the other hand, permanent products do not always accrue from the intervention components being completed. For example, intervention steps that require individuals to make qualitative judgments about behavior or work or the appropriateness of social responses are not conducive to creating permanent records. While permanent products are potentially more efficient, take less time and effort, are less reactive and potentially more accurate than other methods they have 
limited applicability and are not always feasible when to measure particular intervention components.

\section{Direct Observation}

Direct observation is the systematic observation of behavior in applied settings. The same process can be used to measure treatment integrity in the classroom or to videotape intervention for later coding by experts. In observing treatment plan implementation it is necessary to specify clearly in objective operational terms the components of the intervention to minimize inference on the part of the observers. Treatment adherence is generally measured as percent of treatment steps completed. That is, intervention steps are broken down into measurable steps and the occurrence and nonoccurrence of each treatment component is assessed. This measure provides the degree to which treatment integrity of each treatment component has occurred over observation sessions. An advantage of direct observation is that observers can calculate percentages over time and relate the degree of treatment integrity to changes in the dependent variable (Gresham, MacMillen, Beebe-Frankenberger, \& Bocian, 2000).

Notwithstanding its apparent objectivity, and potential to capture a large portion of intervention components, it is the least common method used to assess treatment integrity. Direct observation is resource intensive and involves trained and reliable observers to assess treatment integrity in naturalistic settings. Multiple observers are sometimes necessary to observe multiple sessions over time to capture all intervention components. In addition, direct observation may produce reactivity among those implementing the intervention, that is, high integrity may occur only on those occasions when observers are in the treatment setting. Nonetheless, direct observation is considered the most reliable method for assessing implementation (Durlak, 1998; Duesenbury, Brannigan, Hansen, Walsh, \& Falco, 2005). 
Adherence to treatment plans has been the dominant measure in consultation research even though data suggests possible ceiling effects and multidimensional models of treatment integrity have been proposed. Some preliminary research (Hirschstein et al 2007; Dusenbury et al. 2005) on adherence, duration, quality of intervention, program differentiation and participant responsiveness suggest that each of these dimensions can be individually assessed and are capable of predicting learner outcomes (Sanetti \& Kratochwill, 2009) and as a result should be included in treatment integrity assessment. Two strategies for estimating integrity were proposed by Gresham et al., (1993): 1) Component integrity, which estimates average integrity of components and 2) daily integrity an estimate of all components combined. These two global estimates can be applied to measuring Dane and Schneider's five dimensions of content and process (Power et al., 2005). While evidence suggests using a multimethod approach to measure multiple dimensions of treatment integrity, to date, there have been few empirical studies designed to measure the qualitative aspects of treatment integrity with the majority only measuring adherence. With that in mind, many researchers (e.g., Noell, 2008) now recommend a multimethod approach to assessing multiple dimensions of treatment integrity.

\section{Enhancements to Treatment Integrity}

Treatment integrity is important for many reasons, several of which relate to information about the interventions while other reasons are concerned with legislative mandates. For example, as Perepletchikova and Kazdin (2005) have pointed out that information about which components of an intervention may be critical for successful outcomes can reliably be gleaned only when treatment adherence is monitored. In addition, when intervention results are less than desirable treatment integrity data can provide valuable insight into why (Leff et al., 2010). Finally, it is essential that educators implement and monitor evidence-based practices in the 
context of response to intervention (RTI) to ensure interventions are correctly implemented to give students the best chance for success. While many researchers (e.g., Gresham, 1993; Noell, $2005 \& 2008$ ) strongly suggest that monitoring treatment integrity is crucial because there is a strong relation between the degree of fidelity and outcomes, that is, the greater the fidelity with which effective interventions are implemented the greater the results should be in terms of student outcomes, the research has been inconsistent in this regard.

\section{Current State of Autism Interventions in the Classroom}

\section{Non-Behavioral Interventions}

A variety of intervention approaches are often recommended and used in the treatment of students on the Autism Spectrum regardless of level of research support (Handleman \& Harris, 2000). As a result, teachers are left with incomplete information and often misinformation concerning what is effective and what is considered current evidence-based practice.

Developmental and Transactional models such as Floortime (Greenspan \& Weider, 2003), and the Colorado Health Sciences Program or Denver Model (Rogers \& Delalla, 1991) are two frequently recommended programs for which current research is incomplete. These programs generally consider the reciprocal nature of learning and emphasize relationshipbuilding, joint action routines, and shared experiences, they advocate for a developmental framework for providing individualized environmental support to promote the achievement of core developmental skills and accomplish this through sensory integration strategies to help support children's optimal state of attention, arousal, and emotional regulation. There are current and ongoing research efforts involving these programs as well as a sizeable research base (Greenspan \& Weider, 1997, 1998, 2001, 2003; Rodgers et al; 1986), however, none are as yet 
research validated. Simpson (2005) suggests to be research validated treatments need at least two experimental studies or minimally nine single-case research studies to establish the treatment as effective. Recent studies that have showed sensory integration strategies to be effective (Pfeiffer, Koenig, Kinnealey, Sheppard, \& Henderson, 2011) are generally considered pilot investigations and their effectiveness has not been examined specific to autism. Landa (2007) states that the efficacy of these practices are not supported by experimental studies, while Simpson (2005) argues that while supporting and convincing evidence for approaches such as Floortime are lacking, they nonetheless have potential to be efficacious interventions for students with autism.

The Treatment and Education of Autistic and Related Communication-Handicapped Children (TEACCH) program (Ozonoff \& Cathcart, 1998) is another often-recommended approach. This approach focuses on engineering learning environments and includes schedules of activity, individual workstations and visually guided cues to promote organization, independence, and task completion. Simpson (2005) classifies TEACCH as a promising practice. He states that its methods have emerged as having efficacy and utility for students with autism; however, the intervention requires additional objective verification.

Evidence from quasi-experimental studies has demonstrated that well executed developmentally based approaches have produced gains in students with autism, particularly in the areas of communication. Greenspan and Weider (1997) reviewed outcomes of 200 children with autism in DIR Floortime programs and found that $58 \%$ had "very good outcomes" in the spontaneous use of communication at both the preverbal and verbal levels. But, due to methodological shortcomings and no formal measures of language, it is difficult to draw strong conclusions with regard to the effectiveness of this approach. 
A multiple-baseline study was undertaken to determine the effectiveness of a developmental, social-pragmatic intervention on the spontaneous use of speech by preschool children diagnosed with autism (Ingersoll, Dvortcsak, Whalen, \& Sikora, 2005). Spontaneous increases in speech were noted, but researchers cautioned that these findings offer only the earliest support for using a developmental, social-pragmatic language approach with young children with autism. In short, several approaches (Developmental, Transactional, SensoryIntegration...) show promise for students with autism, but still lack the necessary scientifically based research to be considered current best practice.

\section{Behavioral Interventions}

Behavioral interventions have their roots in principles of operant conditioning principles and follow antecedent-behavior-consequence chains (Newsome, 1998). These treatments grew out of the emerging field of applied behavior analysis in the 1960's, which was based on the scientific principles of behavior, or the experimental analysis of behavior. The interventions based on applied behavior analysis employed the general laws of learning to improve socially significant behaviors of individuals with development disabilities and autism. Initial treatments frequently used procedures called discrete trial instruction or discrete trial training (DTT) for treating children with autism. The context of DTT involves a highly structured learning environment that includes the following five components: antecedent or discriminative stimulus, prompt, response, consequence, and inter-trial interval (Smith, 2001). Behaviors targeted for intervention are task analyzed or broken down into discrete sub-skills and taught in a successive manner for which reinforcement is given for either correct responding or for successive approximations. Teaching materials and teaching trials are selected and initiated by 
interventionists who more often than not explicitly prompt the child's behavior. Reinforcers, also selected by adults, may be functional, but were often unrelated to the target response.

The discrete trial format was used with success in teaching children a multitude of skills and important behaviors including language, cognitive, social, imitation, and behavior reduction (Lovaas, et al., 1965; Schreibman, 1988; Koegel et al. 1993, Green 2001; Matson \& Smith 2008; Smith, 2001).

Discrete trial procedures were also used in highly intensive early interventions for children with autism. For example, Lovaas (1987) implemented an intensive behaviorally based intervention (30 to 40 hours per week) that focused on the reduction of disruptive behavior and the acquisition of speech and language skills. An experimental group received 40 hours of treatment per week while two control groups received less than 10 hours per week. Half of the treatment group had average IQ gains of 20 points while only two percent of the control groups had similar gains. In a follow up study, McEachin, Smith, and Lovaas (1993), tested both the experimental and control groups on IQ scores, adaptive and maladaptive behavior, and school placement and found that with the exception of one student, experimental group participants had maintained all gains over time.

Eikseth, Smith, Jahr, and Eldevik (2002) compared eclectic treatments typically found in public schools with behavior analytic treatments. The behavior analytic treatment group participants significantly outperformed participants in the eclectic treatment group on all standardized measures of cognitive skills, language skills, and adaptive functioning after the first year. Only scores on the Vineland Test were statistically significant, however. In another study that compared the effects of behavior analytic interventions, eclectic interventions, and interventions in small groups, the behavior analytic group significantly outscored the other 
groups in all skill domains on mean standard scores (Howard, Sparkman, Cohen, Green \& Stanislaw, 2005). It should be noted that several studies using behavior analytic techniques found only modest gains (Smith, 1999; Green, 1996).

In a study considered a close replication Lovaas' original study, Sallows and Graupner (2005) randomly assigned children to either an ABA treatment group or an ABA group managed by parents. All children made large gains on all measures including IQ, language, social and adaptive skills. Forty eight percent of the children were successful in regular education programs. In a retrospective design study Eldevik, Eikseth, Jahr, and Smith (2006) compared low intensity ABA and eclectic approaches on measures of IQ, language and adaptive functioning. While gains were not as large as in high intensity services, the ABA group scored substantially higher on all measures except adaptive functioning. Finally, Eldevik, Hastings, Hughes, Jahr, Eikseth, and Cross (2010) conducted a meta-analysis on 16 group design studies that compared behavioral interventions with other types of interventions. A total of 309 children were included in the behavioral intervention groups, 105 were in a control group, and 39 children received interventions in a comparison group. IQ scores and adaptive behavior scores were significantly higher in the behavioral intervention groups.

While discrete trial formats have produced impressive results, the approach has been criticized on the bases of several important limitations. For example, the highly structured and adult-directed nature of DTT and the use of artificial reinforcers are not representative of the normal adult-child interaction (Schreibman, Kaneko, \& Koegel, 1991). It has resulted in tight stimulus control that has produced, at times, a prompt dependency that limits spontaneous responding and generalization of behaviors. In addition to being highly structured, DTT is also highly intensive and requires a great deal of effort from interventionists. 


\section{The State of Evidence-based Practice}

In the past decade there has been an increased commitment in education to implementing evidence-based practices (EBP). The U.S. Department of Education (2007) has underscored the necessity for educational practitioners to begin using assessment and instructional procedures that have scientifically-based research support. Evidence-based practices and best practice guidelines ensure that services are based on reliable and valid research and sound judgment. Efficacy and effectiveness of procedures are significant components of EBPs and only practices that have been replicated in different settings, with different learners, and by different investigators may be recommended for general practice (Hedge, 2003). Evidence-based practices are supported by research utilizing causal research designs that meet nine out of ten quality indicators and produce robust, positive, and socially valid student outcomes (Cook \& Cook, 2011).

The Association for Behavior Analysis issued a report (Barrett et al., 1991) in which they emphasized that all children have the right to effective instruction that includes empirically validated hierarchies or sequences of instructional objectives and measurable performance criteria. Students, according to the report, are also entitled to assessment procedures in which decisions are based on objective, instructional-based measures of performance, with attention to data collection and analysis. Lastly, according to the report, students are entitled to exist in school environments in which the focus is academic achievement and progress and unacceptable behavior is discouraged.

Several fields of study closely allied to special education have undertaken the task of how best to determine evidence-based practices. The Task Force for the Promotion and Dissemination 
of Psychological Procedures (Chambliss, 1998) has delineated criteria for well-established and probably efficacious treatments in clinical psychology. The Task Force for the Study of School Psychology (2003) has made available a detailed description of the research base that provides evidence of efficaciousness of interventions. According to Kratochwill and Stoiber (2002) consumers can use this information to "draw their own conclusions" about whether an intervention has a sufficient research base. The What Works Clearinghouse (2003) rated interventions for general education in terms of their effect which could be positive, potentially positive, potentially negative or negative. All of these approaches developed their criteria based on extensive review and discussion of the issues of research design, quantity of research, methodological quality, and magnitude of effect.

Recently the National Standards Project (2009) as part of the National Autism Center (NAC) initiated a study (major undertaking) to determine the degree to which research supports current interventions for individuals on the Autism Spectrum as well as to highlight the limitations of all interventions regardless of research support. The goal of the National Autism Center is to advocate for evidence-based treatment approaches and share information with families, educators and other professionals. To accomplish this task the Project members began with the development of a Scientific Merit Rating Scale. The Scale was applied to each study as a way to objectively evaluate the strength and soundness of the scientific methodology used in the studies and to determine if the results were valid and could be expected in other studies using similar methods. The Scientific Merit Rating Scale consisted of the following five (5) dimensions listed in order of importance: experimental rigor of the research design; quality of the dependent variable; evidence of treatment integrity; demonstration of participant ascertainment; and generalization of data collected. 
In addition to the Scientific Merit Rating Scale, a Treatment Effects Rating was developed and applied to each study to categorize interventions as beneficial, ineffective, adverse, or unknown. Rating studies on both the strength of methodology (methodological soundness) and treatment outcomes was deemed to be equally important in an effort to judge the efficacy of studies. For example, a strong research design was necessary for researchers and consumers to believe outcomes were valid in studies whether an intervention was found to be effective or not. Both rating scales were applied to a total of 775 research studies from which 38 educational and behavioral intervention strategies or intervention classes were identified.

Issues relating to quality of research studies, quantity of studies for each intervention, and uniformity of research findings were considered as each intervention was placed into one of the following categories on the Strength of Evidence Classification System: a) Established, meaning there is sufficient evidence to label the treatment as effective; b) Emerging, several studies demonstrate treatment effectiveness, but more quality studies are needed before a final determination can be made; c) Unestablished, suggesting little or no evidence available from which to draw firm conclusions pertaining to treatment effectiveness; and d) Ineffective/Harmful, sufficient evidence suggests treatment is ineffective.

The National Standards Project, in the final analysis, identified eleven (11) treatments as falling under the established category. A dominant trend found among the established interventions was that they represented almost exclusively interventions derived from behavioral literature. That is, the extensive and diverse behavioral literature provided broad theoretical support for a full two-thirds of the interventions determined to be established and predominant support for $75 \%$ of the remaining one-third of interventions. A few examples of established treatments include: cueing, prompting and fading procedures; priming, stimulus variation and 
time delay; mand training; modeling; reinforcement schedules; successive approximation; task analysis; verbal operants; discrete trials; student to teacher ratio; and naturalistic teaching methods. Literature representing developmental considerations provided theory upon which the remaining interventions were based.

Several non-behavioral based interventions were categorized as emerging and in need of further empirical support. Therefore, while the National Standards Project (2009) reported that most treatments found to be established derived from behavioral theory, they concluded that it is imperative to continue research on non-behavioral based interventions whether in isolation or in combination with behavioral interventions.

Despite this research base, consistent and systematic application of treatments based on behavior analytic techniques is still lacking in most classrooms for students with autism. It is fairly evident that in many classrooms for students with autism, teachers are providing a hodgepodge of approaches that are not necessarily based on scientific support or current bestpractice guidelines. Even in classrooms where teachers intuitively use procedures recognized as behavior analysis, the precise application of these procedures is lacking.

The next section provides a detailed description of the Competent Learner Model (CLM); a model based on scientific principles and research-validated strategies from Applied Behavior Analysis (reinforcement, prompting/fading, stimulus control...), Direct Instruction (General Case Instruction, correction procedures, scripts...), and Precision Teaching (daily data, fluency...). It was developed to get these evidence-based and established strategies into the hands of teachers and paraprofessional as efficiently as possible and to improve outcomes for students with autism and other pervasive developmental disorders (PDD). 


\section{Competent Learner Model}

The Competent Learner Model (CLM) represents a behavioral model of intentional teaching that views learning as the result of individualized instruction across learning environments (Tucci, 2005). Intentional teachers are defined as those who act purposefully with a plan to accomplish a goal (Epstein, 2007). The CLM is a multi-component package that includes as its foundation an appropriate curriculum, effective instructional strategies that are listed as research validated by the National Standards Project (2009) and other researchers (Cook, Tankersley, \& Landrum, 2009; Simpson, 2000; ), instructional conditions and possible ways in which they can be arranged and rearranged to bring about learning. An integration of applied behavior analysis (ABA), direct instruction (DI), and precision teaching (PT) provides the theoretical foundation for the individual components of the CLM.

The CLM contains the tools necessary for educators and parents to implement effective and sustainable research-based interventions with naïve learners who present challenging learning problems and have difficulty participating in typical learning environments. Specifically, learners of all ages who do not participate in usual instructional conditions, exhibit challenging behavior problems in order to escape or avoid instructional conditions, and/or are missing basic learning-to-learn skills or "repertoires" should benefit from CLM programming.

As the name suggests the CLM seeks to develop competent learners. To accomplish this task, the CLM is designed to effect the development of skills that are necessary for naive learners to solve problems for which they have not been explicitly taught to decode. These skills not only form the basis for problem solving, but also aid in the process of generative behavior or discovery learning. According to Tucci et al., (2011) the development of seven competent learner repertoires is the intended outcome of the CLM. They are the targets of intervention and include 
talker, observer, listener, problem solver, reader, writer, and participator. The repertoires are operationally defined in terms of the learner's knowledge, skilled responding, and social and ethical practices. That is, the learner knows what to do (knowledge), does it well (skilled responding), and does it under appropriate circumstances (social and ethical practices). Tucci (2004) suggests that a repertoire is a dynamic entity consisting of a variety of response forms that are emitted under identifiable conditions. They are considered foundational skills and when acquired by learners will combine and re-combine making acquisition of new behaviors without explicit instruction possible and probable (See section on direct instruction and case-based instruction). Finally, a competent learner is one who acts effectively in novel circumstances and the mastery of the competent learner repertoires is a necessary prerequisite to the process of discovery learning (Tucci 2011). In relation to the seven repertoires, a competent learner can participate and persist in a difficult tasks and problem solve to work out problems. She will observe her surroundings, listen to follow directions and talk to others to describe and explain events to obtain what is needed. Finally, a competent learner will use read text to complete a task and write down text to perform a task. Skinner's (1957) analysis of verbal behavior provides the theoretical foundation for the seven repertoires included in the curriculum that form the learningto-learn skills taught in the CLM.

Finally, the CLM is guided by "The Right to Effective Education” (Tucci, Swatsky, Yurich, Scutta, \& McMahon, 2011) and is focused on classes of new practices that are in line with the report. The first practice is to implement the curriculum with fidelity. According to Tucci et al., (2011) this involves developing learning situations that promote the development of desirable behaviors and instruction that is provided to correct deficits. The second practice is to conduct curriculum-referenced assessment so that instructional decisions are based on sound 
assessment practice. The third practice is to deliver evidence-based practices. The fourth new practice is to arrange and re-arrange contingencies. According to Tucci, et al., (2011) this requires administrative support and resources in order to use the most effective and efficient educational practices. It also requires individualized instructional planning through a careful and deliberate analysis of the existing contingencies.

\section{Theoretical Background}

Competent Learner Model procedures derive from three distinct theoretical perspectives on learning: Direct Instruction, Precision Teaching, and Applied Behavior Analysis. All three are used to formulate, deliver and monitor instruction. Skinner's analysis of Verbal Behavior provides the theory for seven fundamental repertoires taught in the CLM.

\section{Direct Instruction}

Direct Instruction is a systematic, empirically derived instructional technology that includes a set of teaching procedures and programming principles based on instructional design research and verified design principles (Binder, \& Watkins, 1990). Watkins $(2008,2010)$ described DI as a system that integrates the design of curriculum with the delivery of effective research-based instruction. DI has been research-based and research validated during thirty years of development. The goal of DI is to develop and organize teaching sequences and materials to produce the greatest amount of learning using the least amount of examples so teachers can be more effective and efficient with the ultimate goal of "catching-up" disadvantaged learners to their typical peers. The main components include program design, organization of instruction, and teacher-student interactions. 
The initial basic research for DI was in the areas of communication and knowledge structures. According to Binder and Watkins (1990) the research on communication examined how sets of stimuli are similar and different. The principles derived from this research were applied to the design of logical and effective teaching sequences. Teaching sequences based on these principles promoted clear and unambiguous presentations that lowered the probability of students learning misrules or failing to respond to appropriate examples (restricted generalization) or responding to inappropriate examples (overgeneralization). Research on knowledge structures on the other hand, analyzed similarities among cognitive knowledge structures. This analysis identified a logical organization and classification of structures from simple to complex as well as five juxtaposition principles (wording, setup, sameness, difference, and testing) to guide the selection, sequencing, and presenting of examples and non-examples of concepts. This provided instructional designers with the ability to organize curriculum to aid in clarity when communicating to learners and to allow similar concepts to be taught in a similar manner, which also promoted the goal of effective and efficient instruction.

The roots of DI principles can be traced to a particular theory of knowledge that describes how individuals induce and apply knowledge. That is, how individuals use examples to form general ideas and how they apply that knowledge to new untaught examples. This philosophical approach together with principles derived from research on communication and knowledge systems formed the bases for the design of DI curricula, methods of instruction, and organization of knowledge forms as well as the many features that make-up DI programs.

One important feature of DI is general case instruction in which generalized strategies were developed and taught (e.g., sound blending) to equip students with the skills to learn on their own without explicit instruction. This is an important feature of DI and has implications for 
students on the autism spectrum because of the emphasis on stimulus control (Horner, Bellamy, \& Colvin, 1984). Another feature of DI is its emphasis on organizing curriculum in tracks. This allows for the tasks to be interspersed with other tasks instead of presenting a single task per instructional session. The CLM takes advantage of tracks by sequencing activities that integrates units across multiple lessons and repertoires to promote the development and maintenance of skills.

The explicit nature of DI instruction distinguishes it from other instructional programs. That is, to ensure explicit and consistent instruction DI presentations usually take the form of a "scripted" format that teachers follow so that the language of instruction is consistent, concise, and logical (Kim \& Axelrod, 2005). DI scripts strive to create "faultless communication" to maximize clarity and minimize ambiguity. Kozloff (2004) describes it as logically technically proficient communication. One advantage of scripted lessons is that it provides consistency and predictability regardless of who delivers instruction. As a result, parents, paraprofessionals, and others can deliver instruction and provide additional support to students with autism spectrum disorders.

Instructional formats are another important feature of DI. Formats are designed to simplify presentations and to be used across similar tasks. That is, when an instructor learns and uses a format for one type of exercise, she will be prepared for similar exercises. Other important features of DI include small groups, pacing, responding in unison, signals, and correction procedures. The CLM (Tucci, 2004) uses all of these features extensively in curriculum design, methods of instruction, and organization.

DI was compared to twenty other instructional models in the Project Follow Through study (1965) and was found to produce greater benefits in basic skills, conceptual skills, and self- 
concept. With at risk students, students with lower IQs, and general education students, DI produced improved scores, as much as one year's worth of achievement in reading and math and on the Wide Range Achievement Test (Gersten, Becker, Heiry, \& White, 1984). Positive effects on student achievement were also found when DI was used in school reform (Boreman, Hewes, Overman, \& Brown, 2002). Limited research exits on the effects of applying DI to instruction of students with autism; however, two recent studies (Flores \& Ganz, 2007; Ganz \& Flores, 2008) found the components of DI were effective and beneficial for students with autism. A research base for DI and autism is accumulating, but DI is not as yet considered research validated for students with autism.

\section{Precision Teaching}

Precision teaching (PT) was developed in the 1960's by Ogden Lindsley (1964) and was an outgrowth of experimental analysis of behavior. The original basic research was in the areas of reinforcement schedules, stimulus conditions, behavior shaping, and discrimination. The most important finding of this research as it related to classroom learning and teaching was that measuring the rate or frequency of responses proved to be the most reliable metric or indicator of learning. When Lindsley (1964) developed precision teaching he emphasized this measurement framework and developed the Standard Behavior Chart or Standard Celeration Chart as he called it for teachers to measure and chart their student's learning. The chart was unique in that its semi-logarithmic feature allowed for charting ratios of correct responding and errors with the results displayed in a straight line instead of learning curves. This became the first measure of learning. With this chart, teachers and students could measure acceleration and deceleration of learning across days and make timely decisions with regard to teaching methods and materials that may improve learning. In this way the emphasis was on evaluation and revision. It should be 
noted that PT is not a teaching methodology per se, but is actually a measurement paradigm. That is, with daily precise measurement of learning, a teacher, it is hypothesized, will develop or adapt methods and materials to improve learning based on the frequent daily data.

The basic philosophy of precision teaching is based on Skinner's (1964) statement that the organism is always right and will respond in lawful ways to the environment. So if the learner fails, it is the responsibility of the instructional designer or teacher to change the environment in ways that are conducive to learning. All of the many features of precision teaching are based upon this philosophy.

Arguably the most important feature of PT is daily measurement because it lays the foundation for most, if not all, important subsequent decisions. As mentioned above, teachers and students who can self-record can detect important variance in performance and make needed changes in a timely manner. With both teachers and students recording behavior, communication and collaboration becomes second nature and facilitates the processes of making discoveries and solving problems (Lindsley, 1990). One important research finding as it relates to measuring and monitoring progress is that frequency measures (the true measure of learning) taken in brief, oneminute samples per day are sufficient for making decisions (White \& Haring, 1976).

The Standard Chart, as the name implies, is a useful tool that creates a unified system that allows for comparison of results across people and places. As a result of standardization, individuals can look at the chart and make accurate decisions about learner performance based on the trend or slope of the line. Decisions can quickly be made as to accelerating correct performance or decelerating incorrect performance. Charts developed by Lindsley (1972) include daily information based on count per minute, weekly information based on count per week, as well as monthly and yearly counts. 
The use of PT in practice resulted in a number of important contributions to teaching and learning. A significant finding was frequency aims, which represented the idea that teachers should set a number of problems to be accomplished in a set time frame (Haughton, 1972). This resulted in measuring accuracy and speed and was termed fluency building. It required precision teachers to always consider the amount of time for student practice of skills as well as the amount of materials needed in that time frame. Binder (1996) suggests that fluency building has other important implications for learning because it relates directly to the concept of automaticity and its relationship to improved retention, resistance to distraction, and transfer of learning, all of which underlies the concept of generative or discovery learning. In the Competent Learner Model, daily frequency measures, fluency, and discovery learning are built into all aspects of curriculum, teaching strategies, material selection, and environmental arrangements.

\section{Applied Behavior Analysis}

Applied Behavior Analysis (ABA) is the theoretical foundation for systematic instruction in which behaviors or responses are elicited by a specific antecedent or stimulus and are followed by consequences that either increase the probability of future correct responses or decrease the probability of future incorrect responses. Many comprehensive treatment models utilize behavioral approaches grounded in the theory of applied behavior analysis, thus ABA does not refer to a specific intervention program, but may be viewed as an umbrella for various behavioral treatments.

\section{Empirical Bases}

While there is a long history of empirical evidence available to support the strategies and techniques used in the CLM, evidence is just accumulating on the full program as implemented 
in actual practice. The CLM is being used successfully in many schools in several states (Tucci, Hursh, Laniten, 2004). To date, however, little research has been conducted on the program itself. In one case-based example, Warash, Curtis, Hursh, and Tucci (2008), provided anecdotal evidence that demonstrated that the CLM could be used as a tool to deliver developmentally appropriate practices in a classroom for preschool children that integrated learners with disabilities who also exhibited challenging behaviors. The teachers assessed students, collected data and develop lessons using CLM guidelines and curriculum. In several cases the teachers found that by teaching missing repertoires such as participation, the students were able to function more independently and reach their developmental potential.

Slider, Hursh, Warash, and Curtis (2009) looked at the issue of inclusion by integrating a child diagnosed with Autism Spectrum Disorder more fully into a general education classroom. The study was a single case design experiment employing a multiple-baseline design across situations intended to increase appropriate participation and decrease inappropriate participation. The Competent Learner Model was used as a tool to develop observation skills and to identify target behaviors to change for the learner. An Applied Behavior Analysis based token-economy system served as the intervention, and was applied at three intervals across two situations. Each application related to an increase in appropriate participation and a decrease in inappropriate participation. The intervention did increase appropriate participation and decrease inappropriate participation for both situations to which intervention was applied. The authors suggested that the effectiveness of the CLM was not directly measured; however, it did inform the development of the intervention, observations, and data collection skills.

Hineline and Axelrod (2009) conducted a descriptive program evaluation study, in which the objective was to observe implementation of differing behavioral interventions as typically 
implemented in publicly supported education settings. Classrooms observed included the Lovaas-derived model (Discrete-Trial), the Applied Verbal Behavior (VB) model and the Competent Learner (CLM) model. Three questions were asked in the study: 1) which is better in actual practice as implemented in public schools 2) for which children, as characterized by which measures, and 3) with what resources, in terms of conceptual expertise and procedural proficiency of staff? Data was collected from a total of 53 children 27 of which came from classrooms implementing the VB model, 17 from the DT model, and 9 from CLM model. A battery of assessments was administered at the beginning of the study and periodically thereafter providing baseline and outcome measures. Assessments included the Autism Diagnostic Outcome Schedule (ADOS), the Brigance Inventory of Early Development, and the Wechsler Preschool and Primary Scale of Intelligence. The CLM model was found to produce the greatest improvements as measured by the Brigance Academic Subscale. In addition, the improvements in children's outcome measures were generally greater for the C LM model than for the other two approaches. The authors conclude that the CLM model clearly merits further evaluations.

\section{Summary}

It is well documented that a research to practice gap is common in special education classrooms (Snell, 2002; Cook \& Schirmer, 2006). Consultation is one method that experts have used in an attempt to help practitioners implement research-based instructional techniques in their classrooms. Consultation in education has typically relied on hierarchical models in which experts give their expert advice to educational personnel, usually in a single meeting, on how to implement an intervention, design a data collection scheme or implement other types of educational programs. Consultants choose and direct a set of highly specified intervention 
components and monitor whether they are applied in a specific sequence and if all components are included. Typically, communication is unidirectional and consultants do not seek input from educators.

Research has demonstrated that traditional expert models of consultation do not always produce much success in terms of acceptability and sustainability of interventions or adequate intervention implementation integrity,(Power et al. 2005; Leff, et al. 2010), which in turn has a direct effect on student outcomes and poses threats to internal validity. This approach is called into question within a participatory/partnership framework of consultation (Nastasi, Moore, \& Varjas, 2004).

Participatory models seek to be responsive to participants and to link research to practice (Power et al., 2005). The U.S. Department of Health and Human Resources (2001) stated that research should be more responsive to practice and as a result has suggested that investigations using participatory or partnership-based models of collaboration are an important step in that direction. Participatory research takes many forms, but according to Nastasi et al. (2000), the core element is that all stakeholders are involved and actively included in all steps of the research process This process theoretically increases the likelihood that the resulting interventions will be more acceptable, ecologically valid, and sustainable. Participatory models have also been recommended as a way to address issues associated with poor implementation integrity (Schulte \& Osborne, 2003).

In one study, Power et al. (2010) established a community partnership model, which they used to enlist and prepare residents of local communities to serve as paraeducators. In this partnership model roles and responsibilities were co-constructed and training was reciprocal in lieu of being didactic and unidirectional. The dual purpose of the model was to provide sufficient 
training and to seek paraeducator input through ongoing dialogue. The authors illustrated the process of using the community partnership model in the context of the Reading Partners program - a program based on empirically supported strategies. Leff et al. (2011) employed a community-based partnership research (CBPR) model to develop collaboration between researchers and community members to design a youth violence prevention program. CBPR creates conditions to empower community members as equal partners in all aspects of research while also blending empirical support with valuable stakeholder feedback to ensure that interventions are responsive and sensitive to local communities and classroom environments. The goal of CBPR is to develop meaningful and sustainable interventions. The article described the process as partnership-based and iterative.

Principles of partnership-based models have also been used in the design of intervention integrity systems. In an article on the topic of reconceptualizing intervention integrity, Power et al. (2005) described a typical hierarchical model of integrity monitoring and contrasted it with a partnership-based approach. The researchers concluded that monitoring integrity should be formative and collaborative and discussed openly with community partners to increase sustainability and effectiveness of programs. This approach allowed for flexibility while maintaining the systematic application needed for research. In another study using participatory principles to design a system of intervention integrity in urban schools, Gullan et al. (2009) described how they used partnership-based procedures to develop, evaluate and refine an integrity system. This study was unique for several reasons including: 1) intervention integrity was measured on multiple dimensions; 2) intervention integrity dimensions were measured for their impact on participant outcomes; and 3) the mediating effect of integrity measures on intervention outcomes were examined. Studies that integrate program implementation and 
program outcome measures enhance researchers' ability to link outcomes and programs (Duerden \& Witt, 2012).

There are numerous interventions for students with autism including Applied Behavior Analysis (ABA) programs, Project TEACCH, the Colorado Health Sciences approach, and many others. One study carefully considered peer-reviewed outcomes of these interventions and found only ABA programs demonstrated convincing evidence for increasing adaptive behavior while reducing maladaptive behavior (Smith, 1999). Some subgroups of children benefited from programs not based on ABA principles, but most showed little improvement. In short, interventions designed around principles of applied behavior analysis are considered evidencebased practice for students with autism. These practices are backed by research that employs causal designs, meets essential quality indicators, shows robust, positive, and socially valid effects and includes multiple high quality studies (Gersten \& Horner, 2005).

Recently, a program evaluation was undertaken to determine which of several ABA interventions currently used in practice were more effective (Hineline \& Axelrod, 2009). The study compared the Discrete-Trial (DT) model, Applied Verbal Behavior (VB) Model, and the Competent Learner (CLM) Model. The researchers attempted to determine which model was better in actual practice, how they differed in important ways, which children benefited from which model and how resources such as procedural proficiency and stability of staff affected outcomes. The researchers found that all three models produced improvements but the CLM produced the greatest improvements in academic areas.

The CLM was developed as a tool for educators to aid in instructional delivery in order to increase the educational success of children affected by learning impairments (Tucci, Hursh, Laitinen, \& Lambe, 2005). The CLM is based on tenets of Applied Behavior Analysis (ABA), 
Precision Teaching (PT), and Direct Instruction (DI) and is used to effect positive change in a learner's abilities. The CLM is unique because it involves not the teaching of specific skills, but rather teaching competent learner repertoires that provide students with the tools necessary to become a competent learner. According to Tucci (2006) students should have the means to become a competent learner and then generalize this process of learning to diverse settings.

In addition to including a coaching component, validated curriculum, validated intervention procedures, and a course of study the CLM also includes a collaborative consultation component that, much like the partnership-based models, can address issues of intervention integrity, flexibility, acceptability, and sustainability. The principles of participatory research derive from the concept of natural adaptation whereby interventions may be adjusted or adapted based on formative data-based decisions (Nastasi et al., 2000). According to Power et al. (2005) adjusting procedures during intervention in response to data while maintaining core intervention elements may improve their effectiveness. Moreover, it is more responsive to participants. The CLM in much the same manner suggests that through collaborative consultation teachers, instructional aides, and parents (i.e. community partners) will acquire not only the preparation to implement CLM components (i.e. critical components), but also the ability to arrange and re-arrange contingencies (i.e. natural adaptation) as needed. The CLM collaborative consultation process provides teachers, instructional aides, and parents support from the consultant to assess the contingencies that are in place, rearrange the contingencies to develop Competent Learner Repertoires, observe the effects, and further rearrange the contingencies as needed. According to Tucci (2009), the CLM provides the framework for consultants to form a collaborative partnership-based relationship with educators who through 
daily classroom experience with students have the necessary knowledge and skills to answer the questions that guide educational programming for the CLM.

A need exists to influence teachers to embrace and consistently use evidence-based practices for instruction in their classrooms. In education, particularly in special education, there is a serious gap between what occurs in the classroom and what is documented by reliable and meaningful research as effective instruction (Cook \& Cook, 2011). Teachers continue to use ineffective instructional practices even when effective research-documented practices are available (Burns \& Ysseldyke, 2009). Many reasons exist to account for this including teacher inexperience or lack of training in evidence-based practices at both pre- and in-service levels. In other instances, educators have become increasingly cynical and mistrust researchers and terms such as evidence-based practices considering such terms to be another fad to promote ineffective instructional practices (Cook \& Cook, 2011). In order to bridge this gap and ensure that instructional techniques that meet rigorous research principles in regard to design of research, quality, quantity and magnitude of effect are used consistently in classrooms, innovative strategies that form collaborative partnerships, include teachers in decision making and integrate program integrity measures and outcome measures need to be implemented.

The purpose of this study was to evaluate the impact of a partnership-based model of collaborative consultation on the acquisition and implementation integrity of Competent Learner Model curriculum, teaching strategies and instructional conditions and the subsequent impact on learner outcomes including the development of competent learner repertoires. In addition, this study will attempt to identify key aspects of a partnership between the researcher and teacher, examine how the partnership changes over time and how the changes affect 
intervention implementation integrity of the Competent Learner Model components. Student outcomes will be analyzed in relation to intervention implementation integrity measures. 


\section{CHAPTER 3}

Method

\section{Participants and Setting}

The current study involved participants in a classroom for students with developmental disabilities including autism spectrum disorders. The class was in a large public middle school in a rural area. One teacher and one student participated in this study. The teacher was a first year teacher with a degree in secondary education with a specialty in social studies. She had no previous teaching experience in special education, but is currently pursuing a graduate degree in multi-categorical special education. An instructional aide employed as a paraprofessional in the school district was also in the classroom and worked with the student participant several times throughout the day with major responsibilities including helping to deliver instruction, manage behavior, and provide accommodations. The student participant was 11 years old and was placed in a self-contained special education class. Initially diagnosed as developmentally delayed in all five domains, the student was subsequently administered the Childhood Autism Rating Scale (CARS) and fell within the severely autistic range. The student was recommended to a physician to consider a diagnosis of autism, which the physician confirmed.

The classroom consisted of two desks located at one end of the room, multiple desks in the middle, and a play area in the back of the classroom. A large White Board was located on the wall in the front of the classroom and there were several desktop computers throughout the room. In class the student rarely followed directions and was noncompliant. As a result, little inclusion was possible at this time. The student had very limited interactions with his peers and sat at his own table during breakfast away from the others. When the student became upset about something or there was a change in his schedule/routine he tended to become aggressive and 
may bite, hit, or kick his teachers or peers. Staying on task was difficult and the student required frequent prompting on assignments. There were days he seemed to be extremely tired and there were days he was very hyper and paced around the room flapping his hands. Both behaviors made academic tasks much more difficult to accomplish. The student also exhibited selfstimulatory behaviors with his hands and made frequent loud laughing and other noises.

The student used verbal speech and contact gestures such as leading, pulling or manipulating another's hands to communicate. His speech was typically used in stereotypical, repetitive and restricted ways. His utterances were limited to two-to-three words and were generally telegraphic (i.e., contains nouns and verbs only) and although he used multi-word utterances to communicate, they usually referred to a single word or a label for a specific event or situation. For example, he might say "bathroom, thank you, please" to communicate the need to use the bathroom. His communicative acts appeared to be limited to requesting preferred items/needs or protesting and he did not engage in social communicative interactions or communicative turn-taking or answer "wh" questions. He became easily frustrated when he didn't get what he wanted and screamed and engaged in self stimulatory behaviors. The student responded to prompts from teachers and aides and imitated words and social phrases. These instances were, however, generally examples of echolalia as the speech was not used meaningfully. The student responded in the same stereotypical, repetitive and restricted ways when he used communication devices (speech generating devices, communicative iPad apps, etc.) and simply touched all the pictures on a board and did not use them communicatively.

The target school was situated in a rural area. The school was predominantly Caucasian with about $10 \%$ minority students. At least $75 \%$ of the students in the target school were eligible for free and reduced breakfast and lunch. 
Multiple participants (i.e., teacher and student), were involved in this study and served as his or her own control. The participants were selected based on the purpose of the study and on the basis of convenience.

\section{Measures}

Four types of instruments were used in this study: (a) instruments to measure the quality of the partnership between the researcher and teacher as well as key aspects and changes over time, (b) instruments to measure consultation procedural integrity (i.e., the degree to which a consultant adheres to particular procedures), (c) instruments to measure treatment integrity (i.e., the degree to which a consultee delivers an agreed upon intervention including adherence to procedures, exposure or number and length of sessions, quality of delivery, and participant responsive), and (d) instruments to measure learner outcomes. Descriptions of the measures are presented in Table I.

Partnership Assessment In community-based Research (PAIR) The teacher completed the PAIR three times over the course of the study. The PAIR (see Appendix A) is a questionnaire that was designed to assess the quality of the partnership between researchers and school partners (i.e., teacher) within a community-based research model (P. Arora, Personal communication). It was used to identify key aspects of the relationship and changes in the partnership over the course of work on implementing interventions. In addition, it was used to assess the impact of a partnership model on sustainability of interventions in a school setting. The measure consisted of 31 closed-ended items comprising five dimensions: Communication, Collaboration, Partnership Values, Benefits, and Evaluation (for definitions of the dimensions, see figure 1). Items were rated on a 5-point Likert scale, ranging from "Almost Never True" to "Almost Always True." An 
open-ended final item (no. 32) was included to assess respondents' view of whether they believed completion of the measure will impact how they work with their partner in the future.

The partnership assessment in community-based research (PAIR) was also used to assess consultation procedural integrity or whether or not the consultant engaged in the proposed model of partnership-based collaborative consultation. Regarding the psychometrics of the PAIR, ecological validity has been ensured through the process of measure development as well as through the use of "experts" from multiple areas. However, the assessment of reliability of the measure is ongoing (P. Arora, personal communication, September 30, 2013). 
$\underline{\text { Table I }}$

Summary of Properties of Measures

\begin{tabular}{|c|c|c|c|}
\hline Construct & Variables & Measures & $\begin{array}{l}\text { Psychometric } \\
\text { Properties }\end{array}$ \\
\hline $\begin{array}{l}\text { Partnership } \\
\text { Orientation }\end{array}$ & $\begin{array}{l}\text { Quality of } \\
\text { Partnership } \\
\text { Sustainability }\end{array}$ & $\begin{array}{l}\text { Partnership Assessment in } \\
\text { Community-Based Research } \\
\text { (PAIR) }\end{array}$ & $\begin{array}{l}\text { Ecological } \\
\text { Validity est. } \\
\text { from experts } \\
\text { Reliability } \\
\text { Ongoing }\end{array}$ \\
\hline $\begin{array}{l}\text { Consultation } \\
\text { Procedural } \\
\text { Integrity }\end{array}$ & $\begin{array}{l}\text { CBPR Partnership } \\
\text { Procedural Steps }\end{array}$ & $\begin{array}{l}\text { (PAIR) } \\
\text { Checklist }\end{array}$ & $\begin{array}{l}\text { Ecological } \\
\text { Validity est. } \\
\text { from experts } \\
\text { Reliability } \\
\text { Ongoing }\end{array}$ \\
\hline $\begin{array}{l}\text { Treatment } \\
\text { Implementation } \\
\text { Integrity }\end{array}$ & $\begin{array}{l}\text { Content Integrity } \\
\text { Process Integrity }\end{array}$ & $\begin{array}{l}\text { CLM Instructional } \\
\text { Session Performance } \\
\text { Checklist (ISPC) }\end{array}$ & $\begin{array}{l}\text { Inter Observer } \\
\text { Agreement }\end{array}$ \\
\hline $\begin{array}{l}\text { Learner } \\
\text { Outcomes }\end{array}$ & $\begin{array}{l}\text { Competent-Learner } \\
\text { Repertories } \\
\text { Problem Behaviors }\end{array}$ & $\begin{array}{l}\text { ISPC } \\
\text { CLM Instructional Formats } \\
\text { Teacher Data Sheets }\end{array}$ & $\begin{array}{l}\text { Inter-Observer } \\
\text { Agreement }\end{array}$ \\
\hline
\end{tabular}


Treatment Integrity Measures. Two aspects of treatment integrity were evaluated. The first was content integrity or the extent that intervention components were implemented and included: 1) adherence to intervention objectives and steps and 2) exposure to interventions including the number, length and frequency of sessions. The second was process integrity or how well the intervention was implemented and received and included 1) quality of delivery of interventions such as the effectiveness, enthusiasm, and preparedness of the interventionist and 2) participant responsiveness or level of participant engagement. More specifically, research related to development of intervention monitoring systems, (e.g., Gullan, et al. 2009; Power. Et al., 2005), suggest that quality of intervention can be viewed across seven variables including: a) interventionist's use of encouragement, responsiveness, use of intervention strategies, and use of time management and b) participant's enthusiasm, interest level, attentiveness, distractibility, and on task behavior.

Treatment integrity was measured through direct observation by documenting adherence to the instructional session performance checklist (ISPC), a treatment integrity checklist listing the instructional components of the competent learner model (see Appendix B). The presence or absence of each component of the ISPC was documented by marking each box with a (+) to indicate expected performance and a hyphen (-) to indicate not performing as expected. Overall percentage was computed for each observation to determine treatment integrity. The researcher completed treatment integrity observations weekly. An independent observer recorded treatment integrity on $33 \%$ of sessions using the ISPC. These were completed near the beginning, middle and end of the study. The independent observer was trained by the researcher during a 20 minute session that involved presenting, explaining, and demonstrating, when needed, each component of the ISPC. Instructions were reviewed before each observation. Reliability or inter-observer 
agreement was computed by a percent agreement formula of dividing agreements by agreements + disagreements (total number of scores) and multiplying by 100. However, because percent agreement method does not account for chance agreements or the possibility raters guessed on some variables due to uncertainty it is considered an inflated index of agreement. As a result, Cohen's Kappa (K) was also calculated to adjust for inflated percent agreement scores. A K score of greater than .70 is considered satisfactory for inter-rater reliability.

Child Outcome Measures. The researcher and teacher collaboratively completed the Competent Learner Model Placement Test to identify the appropriate competent learner repertoires to serve as target behaviors for the student. Target behaviors were based on the learner's current assessed ability for each competent learner repertoire for each curriculum level. This was determined through collaborative discussions during administration of the CLM placement test.

Competent learner repertoires were based on a learning-to-learn conceptual foundation. That is, repertoires were theorized to give learners the tools to effectively navigate novel and ever changing circumstances not just prepare learners to give a standard or correct answer. A competent learner repertoire is dynamic because it consists of many different response forms that are performed under certain identifiable conditions. So that a response form emitted appropriately for instructional conditions [a repertoire] under lesson 1 would hardly be the same as one emitted for lesson 8 or 16 . While the definition of the repertoire is the same, the response form(s) and the instructional conditions under which it is performed are quite different. The operational definition of any repertoire, to be effective, workable, and flexible then must take into account what the learner knows (knowledge), how well the learner performs (skilled 
responding), and if the learner performs the behavior correctly for the given circumstances (social and ethical practices). Examples of operational definitions for selected competent learner repertoires required under the specified instructional conditions for lesson 8 are listed below: Talker 0.001 Asks for Preferred Item or T Action>Approximates Word (i.e., Noun or Verb) for Preferred Item/Action; Preferred Item Displayed (acquisition routine)

Talker 0.001 Repeats Words for Preferred Items or T Actions (i.e., Noun, Verb, or Attribute): Items not displayed (acquisition routine, transfer of motivational control) Talker 0.001 Accurately Repeats Components of T Modeled Words or Sounds for Preferred Item, with Item Displayed, and Gets Item After Saying Sound (discrimination routine, model then echoic)

Problem Solver 0.002 (mand/request) spontaneously asks for item or $\mathrm{T}$ action in more precise form of motor or vocal behavior to get the item or $\mathrm{T}$ action: $\mathrm{T}$ at-hand, shaping (differentially reinforce) more precise forms of "Asking" Behaviors: T at-hand; Engages in FIRM "Asking" behaviors on leaner schedule of reinforcement (acquisition routine) Observer 0.701 (imitate): co-active play (7.0) imitates a Random Series of FIRM Single-Step Action's Modeled by T in "Work hen Play" Context (generalization routine) Observer 0.703 (matching>sorting) (7.1) matches>Sorts 3 FIRM Sets of Similar Pictures to Objects with 1-2 Distracters: with Sample of Object(s) in Containers (discrimination routine, picture to object)

In addition to establishing or strengthening competent learner repertoires, the teacher and researcher collaboratively identified behaviors that interfered with instruction and were considered problematic. The behaviors that were identified through ongoing observations and discussions between researcher and teacher were prioritized and included several problematic 
behaviors that may be related to inadequate development or lack of specific competent learner repertoires were considered targets for weakening. These include: pointing his finger in the face and touching the hair of interventionists, Flapping, refusing to cooperate, cursing, selfstimulatory behaviors and screaming when very frustrated.

\section{Procedures}

In this study the CLM provided the context for a collaborative partnership between consultant/researcher and teacher/school partner based on a community-based participatory research (CBPR) model. In this model both groups worked together as equal and complementary partners to address the need for evidence-based practices in a classroom that served students with autism and other developmental disabilities. CBPR promotes the dual use of empirically backed interventions and partner feedback to increase the chances that interventions are ecologically valid as well as responsive, meaningful, and sensitive to local communities and schools while also increasing the likelihood that interventions will be more sustainable (Leff et al., 2011). This model also has the potential to balance researchers' needs for systematic implementation of interventions with local school needs. In the context of the CLM the researcher conducted ongoing observations in the classroom to establish which competent learner repertoires were present and under which instructional conditions. In addition, the researcher highlighted effective practices and contingencies already in use and assisted in determining how to rearrange existing contingencies to develop repertoires.

To structure and guide the collaborative meetings a typical consultation format was used and included the following phases: (1) Problem Identification and Problem Analysis (2) Intervention Development and Planning (3) Intervention Implementation and (4) Program 
Evaluation (see table 2). The meetings were conducted in the teachers' classroom and lasted approximately 20 to 30 minutes. After the first three phases were conducted and the intervention was implemented the program evaluation meetings were held on an ongoing and recurring bases to evaluate treatment integrity and learner outcomes and decide whether to continue or rearrange current CLM contingencies.

During the first meeting, problem identification and analysis the CLM placement test was administered to determine what competent learner repertoires needed to be established, strengthened, or weakened. The test required collaboration between consultant/researcher and consultee/teacher and was administered to identify and create a learner profile of competent learner repertoires in strength, needing to be established, and needing to be strengthened. In addition undesirable behaviors displayed by the student (self-injurious, noncompliance, annoying...) were identified and analyzed in terms of the function of the behavior. Types of data measures and data collection methods were discussed and analyzed with respect to the various outcome targets. After the initial meeting, baseline data were collected on CLM repertoire(s) and problem behaviors that were collaboratively determined to be in need of intervention.

Once the target behaviors were identified and analyzed for current contingencies the researcher/consultant and teacher/consultee discussed appropriate programming and strategies for intervention during the second phase program development. First, they determined the types of programming required to develop target repertoires. Several types of programming within the CLM model included maintaining effectiveness of consequences, generating response forms and developing skilled responses among others. Next, they discussed basic behavioral operations (presenting stimuli, stimulus control, consequential) and contingencies (prompt/fade, discrimination, direct instruction lessons) that were appropriate for developing or weakening the 
target behaviors. While it was essential that core components of CLM interventions were kept intact when developing the intervention, potential adaptations and modifications were discussed to ensure that the interventions were applicable to the specific student, teacher, and classroom. This blending of empirical interventions with input from school partners combined to potentially create an intervention that was more responsive to the unique needs and priorities of both the teacher (school partner) and the learner while maintaining the critical components of the CLM. In addition, the intervention was more likely to be acceptable to school partners and enhance the goal of sustainability. 
Table 2

Consultation Phases and Tasks

\begin{tabular}{|c|c|}
\hline Phase & Tasks \\
\hline Problem Identification & Conduct/discuss CLM Placement Test \\
\hline \multirow[t]{5}{*}{ And Analysis } & Identify learner strengths and needs \\
\hline & Prioritize and define repertoires to be developed or \\
\hline & weakened (target behaviors) \\
\hline & Identify undesirable behaviors/functions (Targets) \\
\hline & Discuss baseline measures and implementation \\
\hline \multirow[t]{2}{*}{ Program Development } & Identify and develop specific goals for learner \\
\hline & Discuss types of data measures \\
\hline \multirow[t]{4}{*}{ (Initial Intervention) } & Identify target settings \\
\hline & Review CLM evidence-based practices \\
\hline & Develop intervention with input from partners based \\
\hline & On the CLM and link lessons, tasks, and activities to goals \\
\hline \multirow[t]{4}{*}{ Intervention Implementation } & Implement/Observe classroom intervention \\
\hline & Collect intervention implementation integrity data \\
\hline & Collect child outcome data \\
\hline & Review integrity intervention outcomes \\
\hline \multirow[t]{3}{*}{ Program evaluation } & Review outcome data for intervention \\
\hline & Make instructional decisions: continue program as is or \\
\hline & revise (i.e., rearrange contingencies) \\
\hline
\end{tabular}


During the third phase, intervention implementation, the school partner implemented the intervention as discussed in the previous phase. The consultant provided feedback on instructional practices and the partner and consultant collaboratively discussed how to re-arrange CLM contingencies as needed. Intervention implementation integrity data as well as child outcome data was documented and collected.

The final phase, program evaluation, was ongoing and occurred during each meeting after the intervention was implemented. During this phase data were reviewed and graphed in relation to baseline data. Learner progress was evaluated and decisions were made about continuing current programming, revising it, discontinuing it, or continuing to the next lesson if criteria were met. Intervention integrity data were also evaluated to determine the degree to which the core components of interventions were being implemented and to discuss any changes that occurred during implementation. In addition, integrity data were analyzed in terms of its affect, if any, on learner outcomes.

\section{Experimental Design}

The primary outcomes of this study were the student problematic behaviors and teacher integrity to competent learner model lessons. A multiple baseline design across behaviors (Morgan \& Morgan, 2009) was used to provide the basis for establishing causal inference between the introduction of the CLM intervention (independent variable) and changes in the dependent variables which included competent learner repertoires and problematic behaviors displayed by the student participant. The design included two within phase conditions: no intervention baseline and intervention implementation. The independent variable conditions (i.e., different CLM tasks, types of programming, and contingencies) changed as the student participant progressed through CLM lessons and repertoires. These changes accounted for the 
systematic manipulation of the independent variable. As a result, the across behaviors design permitted the researcher to examine effects when the teacher focused on different repertoires (e.g., participation, problem-solving...) for the student participant and as different instructional contingencies were involved when developing the different repertoires.

Treatment integrity data were collected through direct observation of instructional sessions using the Instructional Session Performance Checklist (ISPC). Treatment integrity data consisted of measures of adherence to the critical components of the CLM instructional conditions and measures of duration and number of instructional sessions. These data were graphed for visual inspection and used to assess the impact of treatment integrity on learner outcomes.

Multiple baseline designs use individual cases as the unit of intervention and analysis. That is, interventions were applied to an individual case and actively manipulated by researchers while dependent variables are repeatedly and systematically measured. Specifically, in the multiple baselines across behaviors design the introduction of the independent variable was staggered across different behaviors and points in time to provide multiple phases and multiple repetitions of effects across behaviors. This design structure allowed researchers to determine if a causal relationship exists between the introduction of the independent variable and change in the dependent variable and to rule out threats to internal validity (Levin, O'Donnell, \& Kratochwill, 2003).

To demonstrate evidence of a valid causal relationship between manipulations of the intervention and changes in the dependent measures and to document the strength of the relation, visual analysis of the data was conducted. Initially, a stable baseline phase of at least three points was established to ensure a predictable pattern of responding and a need for change existed. 
After the intervention phase, results were compared between the different conditions to determine if there was an intervention effect. Multiple phases across behaviors were conducted and visually analyzed. Both within and between phases data were analyzed. The within phases analysis generally relied upon measures of level or mean score, measures of trend or slope of the best-fitting straight line, and measures of variability including range and standard deviation. Across phases analysis consisted of measures of immediacy of effect (Kazdin, 1982) demonstrated by comparing the level of the last three points in a phase with the first three points in the next phase to determine how quickly change occurred after introduction of the intervention. Closely aligned with immediacy of effects was the proportion of data points from one phase to the next that overlapped. The more immediate the effect and the less overlap of data points the stronger the inference that can be made in the causal relationship. Finally, data from all baseline and intervention conditions were analyzed for consistency to add further strength to the likelihood of a causal relation.

Partnership data were collected through administration of the partnership assessment in community-based research (PAIR) which consisted of five partnership dimensions: Communication, Collaboration, Partnership Values, Benefits, and Evaluation. The PAIR was designed to assess the quality of the partnership between researchers and school partners and to identify key aspects of the relationship and changes in the partnership over the course of work on implementing interventions. Descriptive statistics were calculated and charted to determine if changes in partnership impact treatment integrity. In addition, data will be used to assess the impact of a partnership model on sustainability of interventions in a school setting. 


\section{Interobserver Reliability and Procedural Integrity}

Behavioral observations of the students were completed with the Instructional Session Performance Checklist (ISPC) that is used in the competent learner model. The problematic behaviors were categorized under one or more of the competent learner model classes of behaviors including Injurious to others, self-injurious, property violations, noncompliance, and annoying. The behaviors targeted were touches the hair of others, flapping, and screaming. Because we were interested in changing behavior throughout the day in the natural environment, periodic observational sampling was used. For 33\% of the observations, two independent observers simultaneously observed and completed the ISPC. These inter-observer observations were done throughout the study occurring at three week interval. The independent observers were the researcher and a colleague employed by the board of education. The independent observer was trained on the ISPC by the consultant-researcher. The training sessions lasted approximately 15 minutes and involved instructions and presenting the ISPC from. The independent observer practiced with the consultant before beginning observations for the current study in the classroom. During practice observations $80 \%$ agreement was reached.

To ensure behavioral observations were coded reliably, inter-observer agreement was computed by using the following formula: (agreement/(agreement + disagreement)) $x 100$. However, because percent agreement method does not account for chance agreements or the possibility raters guessed on some variables due to uncertainty it is considered an inflated index of agreement. As a result, Cohen's Kappa (K) was also calculated to adjust for inflated percent agreement scores. A K score of greater than .70 is considered satisfactory for inter-rater reliability. 


\section{CHAPTER 4}

Results

The results of the study are presented below with data related to each question. Data were taken on the quality of the relationship between the researcher and teacher-participant, treatment integrity of implementation of competent learner repertoires, and learner outcomes on target behaviors related to problematic behaviors.

\section{Research Question One}

Research question one investigated the extent to which a partnership-based collaboration was formed between the researcher and teacher and how the relationship changed during the course of the study on key partnership dimensions including: communication, collaboration, partnership values, benefits, and evaluation. Data regarding means and percentages were collected over three administrations of the Partnership Assessment in Community-based Research (PAIR). The PAIR is a Likert-type questionnaire with five choices ranging from 1) almost never true to 5) almost always true. Table 3 includes means, total means, percentages, and total percentages for each dimension for each administration and across administrations. In addition, percent change for each dimension across administrations is included to measure change over time. 
Table 3

\begin{tabular}{|c|c|c|c|c|c|c|c|}
\hline \multirow[t]{2}{*}{ Dimensions } & \multirow{2}{*}{$\begin{array}{l}\text { Means } \\
\text { Admin.1 }\end{array}$} & \multirow{2}{*}{$\begin{array}{c}\text { Means } \\
\text { Admin.2 }\end{array}$} & \multirow{2}{*}{$\begin{array}{c}\text { Means } \\
\text { Admin. } \\
3\end{array}$} & \multirow{2}{*}{$\begin{array}{c}\text { Means/ } \\
\text { Dimension } \\
\mathbf{s}\end{array}$} & $\%$ Achieved & \multirow{2}{*}{$\begin{array}{c}\text { Total \% } \\
\text { Achieved }\end{array}$} & \multirow{2}{*}{$\begin{array}{c}\% \\
\text { Change }\end{array}$} \\
\hline & & & & & $\begin{array}{lll}1 & 2 & 3\end{array}$ & & \\
\hline Communication & 4.8 & 4.8 & 5.0 & 4.8 & .96 .96100 & $97 \%$ & $4.1 \%$ \\
\hline Collaboration & 4.6 & 4.6 & 4.7 & 4.6 & $\begin{array}{lll}.92 & .92 & .94\end{array}$ & $93 \%$ & $2.17 \%$ \\
\hline Partner-Values & 4.3 & 4.3 & 5.0 & 4.5 & $\begin{array}{lll}.86 & .86 & 100\end{array}$ & $91 \%$ & $16.27 \%$ \\
\hline Benefit & 3.8 & 3.8 & 4.2 & 3.9 & $\begin{array}{lll}76 & .76 & .84\end{array}$ & $75 \%$ & $10.5 \%$ \\
\hline Evaluation & 4.6 & 4.6 & 4.7 & 4.6 & $\begin{array}{lll}92 & .92 & .94\end{array}$ & $93 \%$ & $2.17 \%$ \\
\hline Total Means & 4.4 & 4.4 & 4.7 & 4.5 & $\begin{array}{lll}.88 & .88 & .94\end{array}$ & $91 \%$ & $6.17 \%$ \\
\hline
\end{tabular}

Means and Percentages for PAIR Dimensions across Administrations

Figure 1 compares the mean scores within dimensions across administrations to display change in the partnership over the course of the study within a dimension. Figure 2 displays total mean scores for each administration to compare changes in the total level of partnership during the length of the study. 


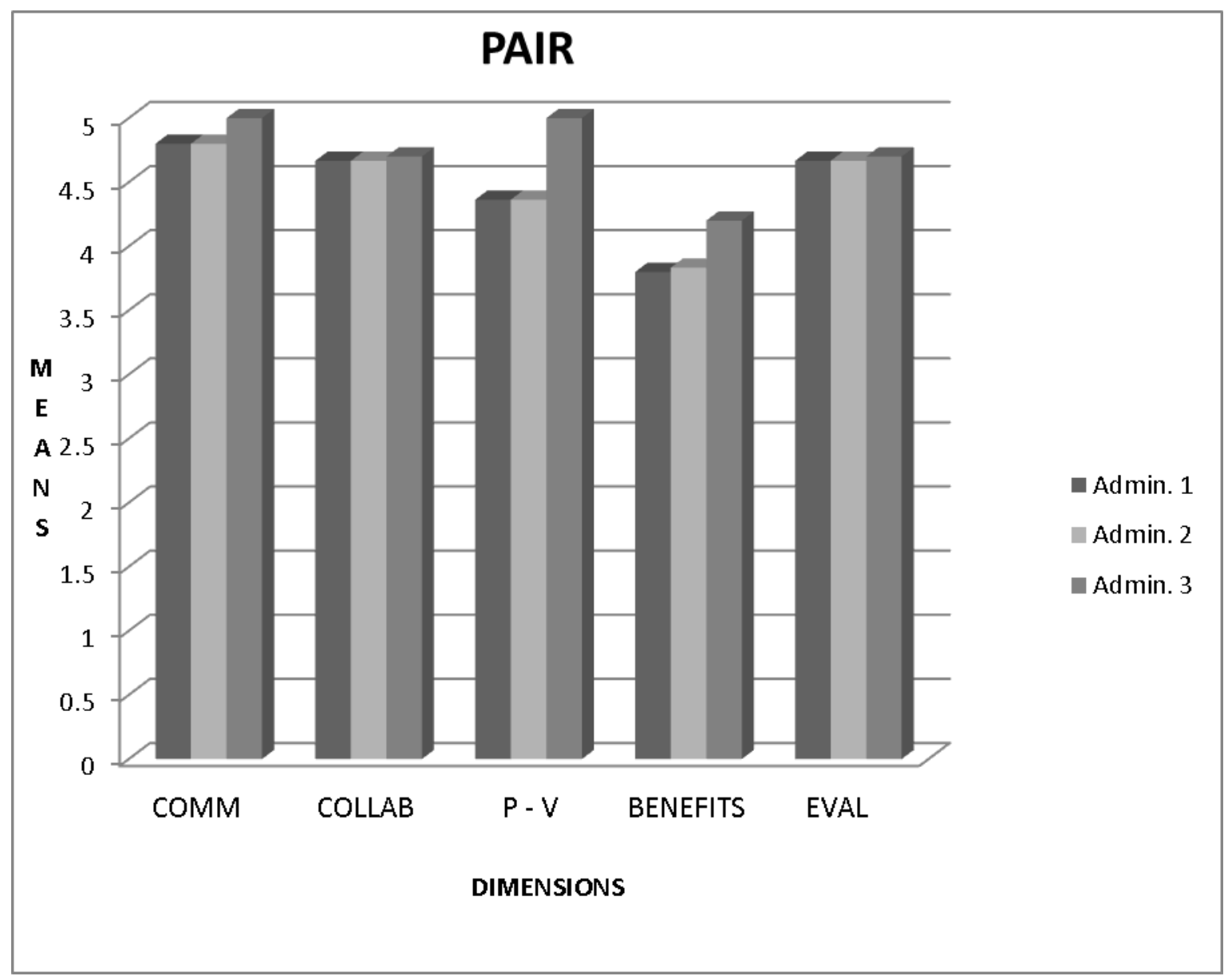

Figure1. Comparison of PAIR dimension means for each administration 


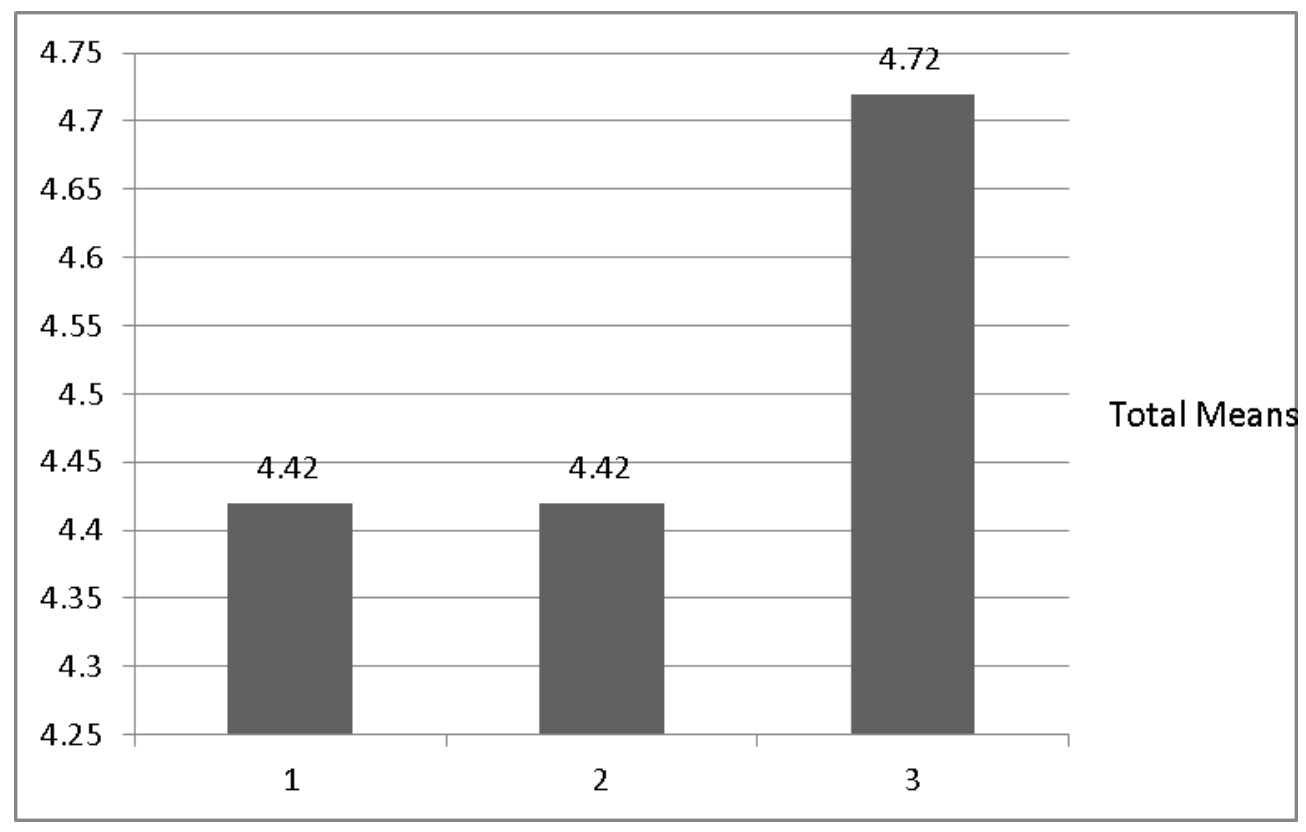

Figure2. Total PAIR means for each administration

The total mean scores on the PAIR remained constant at 4.42 during the first and second administration. During the third administration the total mean increased to 4.47 an increase of $6.7 \%$. In terms of percentages, the first two scores were $88 \%$ and the last was $91 \%$. The average mean score over the three administrations was 4.5 with an average of $91 \%$ of partnership dimensions achieved.

In terms of individual dimensions, communication was the highest with a mean score of 4.8 and $97 \%$ achieved for the study. Communication remained relatively constant changing only 4.1\%. Collaboration and evaluation were the next highest with mean scores of 4.6 and 
percentages achieved of $93 \%$. Collaboration scores changed only $2.1 \%$, while evaluation scores changed $6.17 \%$. Next, partner-values total mean score was 4.5 and percentage achieved was 91\%. However, partner-values changed significantly over the course of the experiment with mean scores ranging from 4.3 to 5 which is a change of $16.3 \%$. Finally, the benefit dimension was the lowest overall with a total mean score of 3.9 and percentage achieved of $75 \%$. However, the benefit dimension mean scores ranged from 3.8 to 4.2 which is a change of $10.5 \%$ the second largest of the dimensions. The percentages achieved ranged from $76 \%$ to $84 \%$.

\section{Research Question Two}

Research question two investigated the level of treatment integrity attained when implementing the competent learner model when provided with partnership-based collaborative consultation. Additionally, research question two investigated whether changes in levels of treatment integrity were associated with changes in the partnership.

There were nine observations to assess treatment integrity including three to assess interobserver agreement. That amounted to one observation a week during the intervention period with $33 \%$ of the observations for interobserver agreement (IOA). This is in line with suggestions from several researchers (McIntyre et al. 2007; Umbreit et al. 2007) although to date there is no consensus on what is considered the appropriate percentage of observations to use for interobserver agreement.

Over the course of the experiment, treatment integrity scores ranged from $71 \%$ to $92 \%$ and interobserver agreement scores ranged from $79 \%$ to $86 \%$ agreement. In studies conducted in schools, measuring treatment integrity is in its infancy and is rarely assessed and reported. In their review of 181 studies, Gresham, Gansle, \& Noell, (2000) found only $14.9 \%$ of studies reported treatment integrity information and the assessed levels ranged from $75 \%$ to $100 \%$. 
Snell, Chen, and Hoover (2006) reviewed 40 studies in the area of augmentative communication and found that $80 \%$ treatment integrity was typical.

To examine agreement between raters interobserver agreement and Cohen's Kappa were calculated. The kappa statistic is used to control for chance observations. There is always the possibility that observers will agree or disagree simply by chance especially when two or more observers must agree when a level of subjective interpretation is required on the part of the observers. Kappa scores range from 0 to 1 where 0 is agreement by chance and 1 is perfect agreement. The following ranges are typically used to interpret the kappa statistic: .01-.20 slight agreement, .21- .40 fair agreement, .41-.60 moderate agreement, .61-.80 substantial agreement, and .81-.99 almost perfect agreement. While no exact guidelines for interpreting interobserver agreement have been established, Horner (2005) suggests that .80 for interobserver agreement and .60 for Kappa are considered acceptable. Table 4 provides information on treatment integrity and interobserver agreement scores for all nine observations as well as kappa coefficient scores for interobserver agreement.

Table 4

Treatment integrity of Competent Learner Model

\begin{tabular}{llll}
\hline Observation & Treatment Integrity & Interobserver Agreement & Cohen's Kappa
\end{tabular}

$1 \quad .71$

2.75

$3 \quad .75$

$4 \quad .79$

$\begin{array}{ll}5 & .83\end{array}$

$\begin{array}{ll}6 & .83\end{array}$

.83

.67

$\begin{array}{ll}7 & .86\end{array}$

$\begin{array}{ll}8 & .92\end{array}$

$9 \quad .86$ 
A Pearson-product moment correlation was calculated to test whether there was an association between the degree of relationship between the researcher and teacher as measured by the Partnership Assessment in community-based Research (PAIR) and the level of treatment integrity achieved by the teacher as she implemented the competent learner repertoires. Overall, there is a strong positive correlation between total partnership means and treatment integrity means, $r=0.83$. However, there was no clear evidence that changes in levels of partnership were associated with changes in levels of treatment integrity. For example, the relationship levels on partnership dimensions did not change during the first two measurements $(88.5-88.5)$ while levels of treatment integrity increased substantially $(73.6-81.7)$. Only during the third measurement did both the relationship and treatment integrity measures show increases (94\% $88 \%$ ), but it should be noted that treatment integrity measures increased for all three measurements so it may be unrelated to changes in the relationship or a direct result of a consistent collaborative relationship.

\section{Research Question Three}

Research question three investigated the impact of the implementation of competent learner repertoires selected and modified through a partnership-based collaboration on learner outcomes, specifically problematic behaviors. Question three also investigated whether different levels of treatment integrity impacted learner outcomes. A combination of visual analysis, percent of non-overlapping data, and effect sizes non-regression effect size measures were used to describe the intervention effects of competent learner repertoires on problematic behaviors. Visual analysis included inspection of data for changes in level, trend, and variability, while effect sizes were calculated using non-regression methods of standard mean difference (SMD) and percent of non-overlapping data (PND). Figure 3 is a multiple baseline across behaviors 
graph that displays baseline measures of problematic behaviors and measures of problematic behaviors after implementation of competent learner repertoires.

In addition, table 5 displays Percent of Non-Overlapping Data (PND) and Standard Mean Differences scores (SMD) for each phase of the graph. PND is a non-regression method for calculating treatment effectiveness for single subject data. It uses the number or percentage of intervention data points that exceeds the highest baseline data point or the lowest baseline data point if the intervention is designed to decrease behaviors. To interpret PND, Scruggs and Mastropieri (2001) suggest that scores below 50\% are ineffective treatments, between 50\% and $70 \%$ are questionable, $70 \%$ to $90 \%$ are effective, and above $90 \%$ are very effective. SMD scores which results in (d) values or effect sizes were also calculated. Effect size scores are more familiar to most readers and allow readers to more easily interpret the effectiveness of the interventions. According to Cohen (1988), d scores of 0.8 and above are considered large and represent effective interventions, while $\mathrm{d}$ scores of 0.5 are considered medium, and $\mathrm{d}$ scores of 0.2 are considered small. 

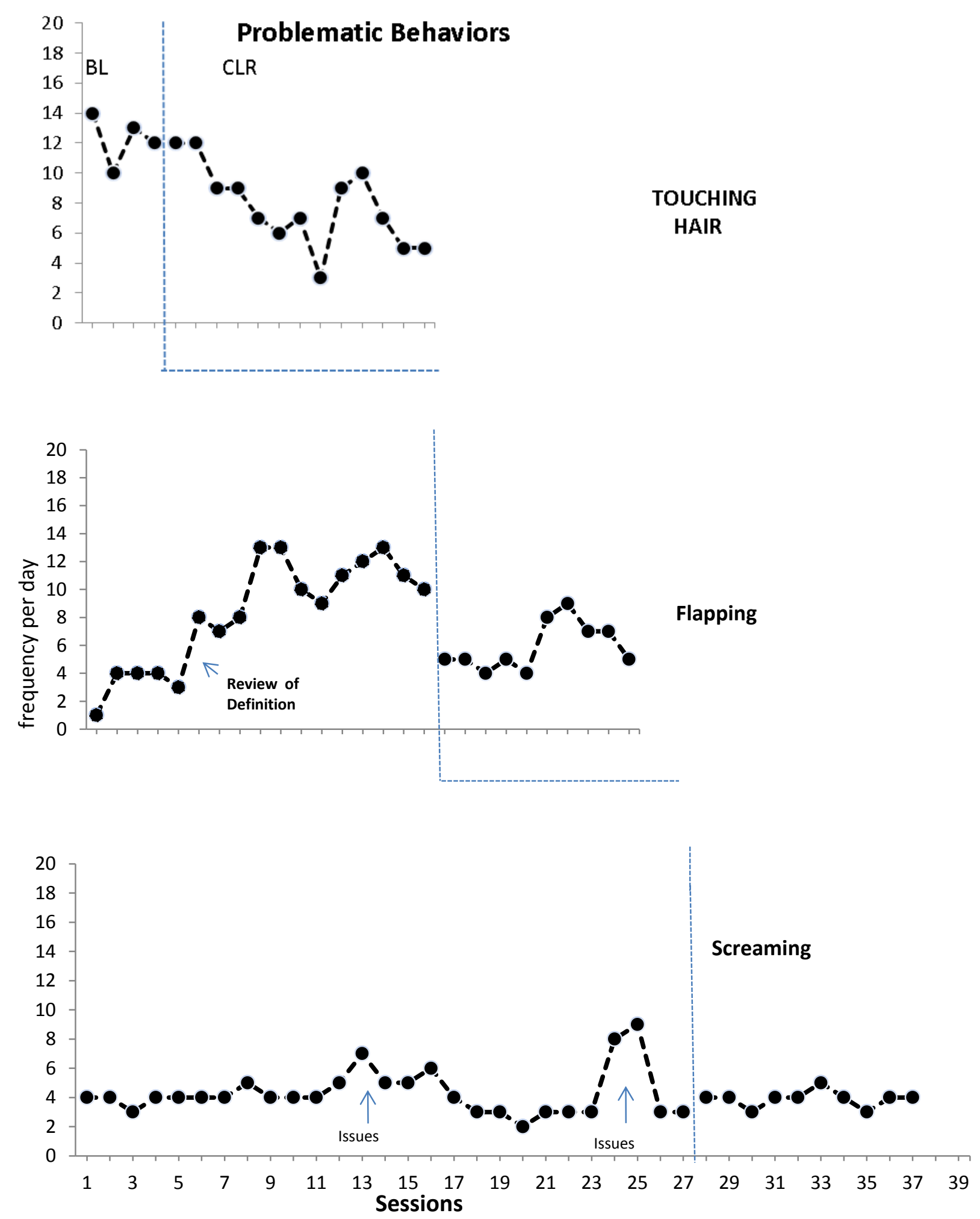

Figure3. Baseline and Intervention Measures of Problematic Behaviors 
Table 5

Percent Non-Overlapping Data and Standard Mean Difference Scores

\begin{tabular}{llll}
\hline Behaviors & PND & SMD & Effectiveness \\
\hline Touching Hair & $76 \%$ & -2.5 & Very Effective \\
Flapping & $60 \%$ & -0.6 & Moderately Effective \\
Screaming & $0 \%$ & -.33 & Not Effective \\
\hline
\end{tabular}

Examination of the graph through visual analysis revealed that baseline measures for the target behavior touching the hair of others were high and relatively stable with a mean of 12.25 and a range of scores from 10 to 14 . During the intervention implementation phase the trend was moderately negative with a slope of -0.45 . Scores ranged from 12 to 3 with a mean score of 7.7 . The percentage of non-overlapping data was $80 \%$ and the standard mean difference effect size was -2.6 , both of which suggest a very effective intervention.

During baseline for flapping behavior the scores were somewhat variable ranging from 1 to 13 . However, after the first week of baseline data the teacher and researcher adjusted the definition of flapping to more accurately reflect the number of occurrences and the function of the behavior. The baseline data were more stable beginning with week two ranging from 8 to 13 . The mean for baseline data was 8.4. For the intervention implementation phase the mean score was 5.9 with a range of 5 to 9 . The percent of non-overlapping data was $70 \%$ and the standard 
mean difference from baseline to intervention effect size was -0.6. Both of these scores suggest a moderately effective intervention effect.

For the target behavior screaming, baseline data were stable with low variability with eighty five percent of the scores in the 3 to 5 range. The several higher scores in baseline may have been the result of issues with medication. The mean for baseline data was 4.4. The intervention phase scores were stable with a mean of 3.9 and low variability with scores ranging from 3 to 5 . The percent of non-overlapping data was $0 \%$ and the standard mean difference effect size between the baseline and intervention phases was -0.33 . Both scores indicate an intervention that was ineffective. 


\section{CHALTER 5}

\section{DISCUSSION}

The main goal of a partnership-based collaboration is to give teachers input in all aspects of intervention (Kelleher et al. 2008). Ultimately, by giving teachers input and control over data collection methods, target behaviors, intervention activities, and intervention modifications it is hypothesized that the intervention will be closer to practice, more socially valid, and teachers will be more invested and willing to learn and use it.

The purpose of this study was to assist a teacher to effectively intervene with a naïve learner by engaging in a partnership-based collaboration to improve treatment integrity of the competent learner model. Teacher ratings of the perceived level of partnership were measured by The Partnership Assessment In Community-Based Research (PAIR). The PAIR is based on research (Leff et al., 2011; Israel et al., 1998; Arora et al., in progress) that suggests mutual trust and respect, open communication, co-equal participation and benefits to partners characterize and are keys to developing successful partnerships. It should be noted that the PAIR is currently undergoing a formal analysis of psychometric properties and should be viewed as a preliminary measure.

\section{Interpretations}

Research question one was designed to investigate the levels of key partnership dimensions of communication, collaboration, partnership values, evaluation and benefits to partners and to evaluate changes in dimensions over the course of the study. Overall, teacher rating on the PAIR reflected teacher perceptions that a partnership was formed and maintained for the duration of the study. 
Communication, collaboration, and evaluation were the dimensions consistently rated the highest throughout the study. After inspecting individual questions, it is apparent that communication and collaboration questions were measuring closely related aspects of partnerships such as participatory dialogue and decision making, negotiation and other relational dimensions (Erchul et al. 2007). For example, communication emphasized open dialogue between partners, resolution of conflicts through discussion, and exchange of ideas, while collaboration emphasized partners working together in an equitable manner, dividing responsibilities, and collaboratively making decisions and determining goals. The evaluation dimension, while not as closely related as the other two, nonetheless involves a commitment from the partners to communicate and continuously assess and rework the partnership. These three dimensions may have measured items more familiar to the teacher and certainly more tangible when thinking about how they affected the relationship. In addition, these three dimensions may have been emphasized more by the researcher because he was trying to develop and maintain the collaborative partnership.

The benefits dimension was rated the lowest over the course of the study, but did show a positive change of $10.5 \%$ from beginning to end. This dimension was intended to measure how the partnership provided tangible benefits and increased scientific knowledge for the teacher. It included questions related to how the teacher could benefit personally and professionally from the partnership as well as how the organization and community could benefit. Rating how the community and organization benefited from the partnership may have been somewhat vague and less tangible to the teacher and less about relational or interpersonal communication that was emphasized by the other dimensions. 
Finally, the partnership-values dimension was also rated relatively low on the first two measurements, but increased $16.8 \%$ on the last. This dimension comprised core values of mutual trust and respect, valuing the partner's perspective and not unlike the benefits dimension included aspects of understanding the culture of the organization and community.

In this case dimensions more focused on relational communication (communication, collaboration, evaluation) were rated higher from the outset and remained that way for the duration of the study. Two reasons may have accounted for this. First, the researcher may have emphasized the open dialogue and co-equal decision making aspects to ensure facilitating that an equitable and collaborative partnership was developed early in the study. Second, the teacher was undoubtedly more familiar with these concepts and perhaps felt empowered by having equal ownership in decision making. Thus, the familiarity with and the tangible nature of what was being measured by these dimensions may have accounted for the higher ratings of these dimensions over the others. While both the benefits and partner-values dimensions had characteristics of communication being measured, the emphasis was more on the community and organizational aspects. The teacher may have initially been uncertain about what was being measured or had difficulty realizing how her organization and community would benefit from the collaboration. That ratings on two dimensions changed drastically over the course of the study may be indicative of the varying nature of key dimensions of partnerships. When evaluating the dimensions at different points in the process it may be necessary to consider more closely the nature of what is being measured. It may be that the benefits and partner values dimensions were measuring more complex and subtle features and may take more time to fully comprehend. 
Research question two focused on the level of treatment integrity attained by the teacher when engaged in a partnership-based collaboration. Treatment integrity is not always reported in outcome studies especially those that involve a third party consultant. When treatment integrity has been reported the study usually involved a traditional directive or prescriptive behavioral consultation model. Levels of treatment integrity attained in these studies have been quite variable ranging anywhere from 50\% to $100 \%$. For example, in school-based studies that focused on behavioral issues treatment integrity levels ranged from $79 \%$ to $100 \%$ (Gresham et al., 1993). In studies that focused on autism and alternative communication treatment integrity levels were in the $80 \%$ range.

Measuring treatment integrity provides valuable information about how much and how well the intervention has been applied. It also allows researchers to draw valid conclusions about functional relationships between interventions and outcomes (Shadish, Cook, \& Campbell, 2002). Nonetheless, only $14.9 \%$ of the school-based studies and only $18 \%$ of the autism studies included operational definitions and assessment of treatment integrity. According to Hagermoser, Sanetti, and Kratochwill (2008) researchers may be reluctant to provide low treatment integrity data when submitting a study for publication.

A partnership-based model of consultation unlike a directive model infuses partnership into the process of designing interventions and therefore has the potential to create more relevant and acceptable interventions (Nastasi et al., 2000). Designing or modifying evidence-based interventions to be more relevant to a particular classroom and more acceptable to a teacher may potentially increase levels of treatment integrity or at least result in adequate levels being used. One study examined treatment integrity given expert-driven vs a partnership-based collaborative approach (Kelleher, Riley-Tillman, \& Power, 2008). In this study results indicated that 
partnership-designed interventions resulted in higher levels of treatment integrity (80-100\%) and less variability than expert-driven interventions $(50-71 \%)$. The hypothesis for this question was that the teacher would implement competent learner repertoires with at least moderate levels of treatment integrity and would also sustain moderate to high levels throughout the course of the study.

The competent learner model is a comprehension and complex intervention based on principles of applied behavior analysis, direct teaching, and precision teaching. It presumes that improvement in competent learner repertoires will lead to improved learning of academic and social topics and reduce problematic behaviors. It involves functional assessments, curriculum, physical structure, delivery of instruction, and reinforcement of learner behavior.

During the first three treatment integrity observations, treatment integrity levels averaged $74 \%$. For the next three observations, the average treatment integrity was $80 \%$ and for the last three $88 \%$. These levels, while not significantly higher than those reported for most expertdriven consultation studies or for those reported by Kelleher, do show a positive trend over the course of the study which supports part of the hypothesis for question two. This is an important finding because several school-based consultation studies have suggested that initial treatment integrity levels were high, but decreased within 1 to 10 days after the initial consultation and training (Noell et al, 1997; Sanetti \& Kratochwill, 2009).

The second part of research question two focused on the potential correlation between partnership-based collaboration and treatment integrity. There was a positive correlation of $\mathrm{r}=$ 0.83 for measures of collaboration and measures of treatment integrity. Generally, research has found that it is not easy to change teacher behavior and it is difficult to sustain any such changes 
(Noell et al., 1997; Witt et al., 1997). In this study the ongoing partner-based collaborations that were engaged in weekly may have provided the support needed to maintain levels of treatment integrity, but this correlation does not provide causative evidence.

While this question focused mainly on third party influences on treatment integrity (collaborative consultation) other student and teacher factors may have contributed as well to the levels of treatment integrity found in this study. For example, the teacher while new to the competent learner model was familiar with the applied behavior principles utilized in the intervention. She was, in fact, observed to be applying various applied behavior analysis methods before the collaboration albeit somewhat unsystematically and imprecisely. This suggests that the teacher's training, views, and philosophy of teaching were compatible with the methods used in the competent learner model and together with the partnership-based collaboration may have influenced treatment acceptability and integrity. In addition, familiarity with the intervention methods possibly lessened the complex nature of the intervention.

Overall the results for question two are mixed. The level of treatment integrity trended up over the course of the study which suggests that implementation of the competent learner repertoires was sustained and the ongoing collaborative partnership and support had a positive impact in producing intervention changes for this teacher-participant. On the other hand, the levels of treatment integrity attained were consistent with and not significantly higher than those attained in the majority of other studies using hierarchical models (Hagermoser et al. 2008). This study does not provide unequivocal support for increased levels of treatment integrity for interventions designed within a partnership-based collaboration. 
Research question three explored the impact of competent learner repertoires on learner outcomes. Additionally, research question three investigated whether different levels of treatment integrity impacted outcomes. The hypothesis was that as the student acquired competent learner repertoires he would develop more control over his environment and rely less on problematic behaviors to express his needs and wants. That is, increases in repertoires would lead to decreases in problematic behaviors. The hypothesis for the second part of the question was that higher levels of treatment integrity would result in better learner outcomes.

To answer this question a multiple baseline across behaviors design was used. In a multiple baseline across behaviors design two or more behaviors are measured concurrently for a single participant. After stable baseline has occurred for the first behavior, the treatment variable is applied while the other behaviors remain in baseline (Cooper, Herron, \& Heward, 1987). The logic that underlies experimental control of multiple baseline designs involves prediction, verification, and replication. For prediction, repeated measures of baseline data provides the basis to determine or predict the likely path of the data if no intervention is applied. So the predicted path can be compared to the actual path after intervention to determine a difference. The verification process involves demonstrating that the treatment variable caused a change in the target behavior while not impacting the other behaviors. This requires behaviors that possess functional independence and that are topographically different. Finally, if behaviors change when and only when the treatment variable is applied across behaviors, we can say we have replicated the effects of the treatment. Three behaviors that were problematic and interfered with the learning process were chosen in collaboration between the teacher and researcher. The behaviors were operationally defined and baseline data was measured. 
The first target of intervention was the student's constant touching behavior in which he would touch the hair of the person providing instruction. Functional analysis data was collected on antecedents or motivational variables and consequences for the behavior. It was determined that the most likely function of the touching behavior was the student attempting to escape or avoid instructional events. As a result, it was decided to give the student task or material choice when feasible by implementing the Talker (mand) repertoire. For this repertoire the student repeats two-word phrases to get what's wanted.

The data for target behavior one indicated clear evidence of a change from baseline to intervention. There was a large change in both trend and level. After implementation of the intervention the target behavior level decreased from a mean of 12.25 during baseline to an intervention mean of 7.8. The baseline data was relatively stable with a low negative trend (slope of -2) and a moderate negative trend (slope of -0.5) during intervention. The standard mean difference was -2.5 which indicates the Talker (mand) intervention was very effective. The target behavior of touching was decreasing, with the exception of days thirteen and fourteen, in the hypothesized direction. The spike in data on days thirteen and fourteen coincided with a spike in baseline data for flapping behavior. This was related to behavioral issues in the classroom.

The second target of intervention was "flapping" behavior. It was determined through observation of antecedent events that the most likely function of flapping behavior was gaining access to preferred items during familiar activities such as art and baking. Therefore, the Problem Solver (mand) repertoire was chosen as the treatment variable. This repertoire requires the student to spontaneously ask for items or teacher actions using short phrases specifying what is wanted. The baseline data for flapping behaviors initially was very low ranging from 1 to 4 and did not appear to reflect the actual number of times the student engaged in the behavior. As a 
result, it was decided to include all flapping behavior that occurred and not just when the student stood up. After the adjustment in what to include as flapping the behavior increased to a range of 8 to 13 . Importantly, the baseline of flapping remained relatively stable and did not appear to be influenced by the introduction of the treatment variable (i.e., Talker repertoire) for behavior one. A stable baseline likely indicates that behaviors one and two were functionally independent behaviors and did not covary. The absence of a generalization effect from treatment one to behavior two increases experimental control and facilitates interpretation of data from graphs one and two.

As evidenced from graph two the introduction of the treatment variable resulted in an immediate and marked decrease in the flapping behavior. After the first week, however, the behavior increased noticeably for two to three days before returning to intervention levels. This increase in behavior coincided with an increase of baseline data for target behavior three during days twenty four and twenty five. This was attributed again to generalized behavioral issues within the classroom.

The behavior targeted for intervention in graph three was a high pitched screaming behavior that intensified as the duration of the behavior increased. The screaming behavior typically occurred when the student was asked to name or label pictures or items in an academic teacher-directed lesson. When asked to name items the student would look away from the pictures and look around the room. After several requests by the teacher to name a picture he would engage in screaming behavior. It was decided that the Observer (tact) repertoire would be implemented in which the student answers with a "yes" or "no" response to the question "Is this $\mathrm{a} / \mathrm{n} \ldots$ _ ? It was hypothesized that having the student answer yes or no would lessen the frustration level for the student and would provide a transition into labelling behavior. For the 
teacher it was an important that the student to display what he knows so she could incorporate it into lessons and IEP goals and objectives

In graph three there was an extended period of baseline data while interventions were applied to target behaviors one and two. The baseline data remained stable throughout the extended baseline period except for two spikes that occurred at the same time and for the same reason as the spikes in graphs one and two. Two things stand out on this graph. First, there was little if any change in level and trend with the introduction of the treatment variable. The baseline mean of 4.4 and intervention mean of 3.9 as well as effect size of -0.33 indicates little to no intervention effect on the screaming behavior. Second, with the introduction of the Problem Solver intervention for behavior two, there was a simultaneous decrease in baseline screaming on graph three. It is not uncommon in multiple baseline designs to occasionally have intervention effects generalize to non-targeted behaviors; however, it may also indicate that the two behaviors covary.

That behavioral covariation would occur suggests that the two behaviors are not functionally independent and are responding similarly to the same intervention (Morgan \& Morgan, 2009). This finding lessens the experimental control of the multiple baselines across behaviors design in which change in the target behavior occurs when and only when the treatment variable is implemented. It makes interpretation of the finding somewhat difficult and makes cause and effect conclusions dubious. On the other hand, these unplanned effects of intervention or behavioral cusps may prove to be useful for the teacher as the problem solver intervention appears to lead to changes in both flapping and screaming behaviors. Rosales-Ruiz and Baer (1997) used the term behavioral cusps to describe these unplanned yet desirable changes. 
Overall the findings for research question three were mixed. While the data for graphs one and two show clear evidence that the treatment variable was effective in reducing target behaviors, graph three clearly does not demonstrate that the treatment variable was effective. Graphs one and two show that there was an immediate reduction in target behaviors followed by a significant spike in the data attributable to a student characteristic variable. Continued measurement of target behaviors, however, showed that the data returned to the levels displayed before the spike occurred. The findings in graph 2 were likely impacted by the behavioral issues that resulted in a data spike. If the data would have continued on the initial path the mean levels for the intervention would have been much lower suggesting a greater effect of the intervention.

Graph three highlights that the baseline data remained steady and stable until the treatment variable for target behavior two was implemented. In addition, when the treatment variable for target behavior three was implemented, the data continued at baseline levels. While this condition limits experimental control, it provides the teacher with valuable clinical information. For example, she may consider targeting several problematic behaviors for reduction when implementing the Problem Solver repertoire for this particular student.

\section{Implications for Practice}

This study was designed to demonstrate the potential success of a partnership-based collaborative consultation on improving teacher treatment integrity of evidence-based practices and on the effectiveness for student outcomes on problematic behaviors. This study was a singlesubject study and the results cannot be generalized to other classrooms. However, the results may have implications for teachers providing instruction to students with autism. 
Students on the autism spectrum sometimes display problematic behaviors that interfere with their interactions and learning (Reichle et al., 1996). Teachers in these classrooms do not always apply evidence-based practices for a number of reasons (Lang et al., 2010; Morrier et al., 2011). This study sought to use a partnership-based collaboration between a researcher and teacher to help the teacher implement evidence-based practices with a high degree of treatment integrity.

Four implications of the study are suggested. Treatment integrity measures are important in order for researchers and teachers in practice to derive valid conclusions about functional relationships between interventions and learner outcomes (Shadish, Cook, \& Campbell, 2002). One implication of this study was that the use of the partnership-based collaboration in which the researcher provided ongoing support and the teacher and researcher were co-equals in decision making may have contributed to sustained levels of treatment integrity over the course of the study. While treatment integrity levels in this study were not on average any higher than those reported in other studies, treatment integrity levels remained high throughout the duration of the study. This is noteworthy because in numerous school-based studies that involved consultation, teachers were able to reach $100 \%$ integrity immediately after training, but within 10 days of training, levels had diminished to anywhere from $0 \%$ to $65 \%$ integrity (Hagermoser, Sanetti \& Kratochwill, 2007). Several factors may account for this finding. First, sharing responsibilities for decision making in all aspects of the process may have led to increased acceptability of the intervention and the process in general. One caveat, however, is that a teacher's acceptance of an intervention is not sufficient by itself to change teacher behavior (Noell et al., 2005).

Second, the intervention procedures were applied within the context and constraints of a real classroom as opposed to a controlled research environment. In this case we had the ability to 
tailor interventions to this particular classroom environment and to use the preferred resources of the teacher. These factors when considered together with increased acceptability may have reduced the perceived research to practice gap and enhanced ecological validity and led to sustained use of the intervention. Research has demonstrated that high levels of treatment integrity are associated with better outcomes and when treatment integrity decreases over time outcomes are vulnerable (Noell et al., 2002; Wilder et al., 2006). Therefore, finding factors that are associated with sustained levels of treatment integrity is important.

Another implication of this study relates to the teacher's training, the intervention used in the study and the amount of teacher change required. It is difficult to change teacher behavior and even more difficult to sustain change (Noell et al., 1997). Research on the role of a collaborative model of consultation in effecting teacher change is mixed. However, Wickstrom et al., (1998) state that collaboration and treatment acceptance are not sufficient to change teachers' behaviors and other factors need to be studied. In this study the competent learner model was used as the treatment variable. The CLM is a comprehensive model that includes focused interventions and strategies that are research based and considered evidence-based practices. The teacher-participant, who was enrolled in a graduate special education program, was observed prior to the study to be implementing strategies similar to those advocated in the CLM although with less precision and less systematically than that required in the CLM. This suggests that there was little or no discrepancy in the teacher-participant's teaching philosophy and that advocated in the CLM. The implication then is requiring the least amount of teacher change and expanding on their current practices as much as possible may facilitate the teacher change needed for implementation of evidence based interventions. 
Another implication of the study involved the use of the Partnership Assessment In Community-based Research (PAIR) to evaluate the range of dimensions needed to form a successful partnership. The PAIR assesses five dimensions including mutual trust and respect, open communication, joint participation, and tangible benefits to partners. In this study the benefits to partners and partner-values were initially rated low but increased as the study progressed. It is conceivable that the PAIR can be used by the researcher and teacher-participant as an ongoing assessment of the quality of their relationship and to adjust the dimensions as needed to improve the partnership. Finally, in the larger context of teacher accountability a broader implication may be suggested. That is, that the partner/coach brings evidence-based practices into the situation and becomes a partner in the accountability process.

\section{Limitations}

This study focused on the effectiveness of interventions in the context of a school setting. The applied nature of the study was associated with several limitations. First, the researcher conducting this study was also a faculty member at the school and had worked with the teacher prior to the study and developed a positive working relationship. This may have influenced the nature of the collaboration. Second, due to the time constraints imposed in the school context the length of the intervention phases of the study were somewhat limited. Additional data from longer intervention phases may have enhanced data analysis or allowed for the possibility of additional phases such as generalization or maintenance phases to be included in the study. The goal of consultation in schools, whether it is collaborative or directive, is for teachers to learn and apply interventions to deal with current problems and hopefully to apply those skills to future problems. The time constraints also prevented the researcher from measuring and documenting the sustainability of the intervention over time. 
The multiple baseline design has some inherent limitations. First, because the study involved only one student, findings cannot be generalized to other settings or students. In addition, because in this study two behaviors covaried it becomes difficult to make conclusive causative statements about the intervention effects on student target behaviors.

In conclusion, this study represented an effort to build a partnership-based collaboration between a researcher and teacher to assist the teacher in the acquisition and use of evidencebased practices to improve student outcomes. The study involved assessment of the quality and changing nature of the partnership, direct observation and assessment of treatment integrity of the competent learner model, and assessment of learner outcomes. The results indicated that a partnership can assist the teacher in acquiring and implementing with integrity competent learner repertoires that can improve learner outcomes. 


\section{REFERENCES}

American Psychiatric Association. (2013). Diagnostic and statistical manual of mental

disorders ( $5^{\text {th }}$ ed.). Arlington, VA: American Psychiatric Publishing.

Barnhill, G., Polloway, E. A., \& Sumutka, B. M. (2011). A survey of personnel preparation in autism spectrum disorders. Focus on Autism and Other Developmental Disabilities, 26, $75-86$.

Barrett, B.H., Beck, R., Binder, C., Cook, D.A., Engleman, S., Greer, D., Kyrklund, S.J., Johnson, K.R., Maloney, M., McCorkle, N., Vargas, J.S., \& Watkins, K.L., (1991) The right to an effective education. The Behavior Analyst 14, (1) 79-82

Bergan, J.R. \& Kratochwill, T.R.(1990). Behavioral consultation and therapy. Plenum Press Binder, C. (1996) Behavioral fluency: Evolution of a new paradigm. The Behavior Analyst, 19, 163-197.

Binder, C., \& Watkins, C. L. (1990) Precision teaching and direct instruction: Measurably superior instructional technology in schools Performance Improvement Quarterly, 3(4), 74- 96 Retrieved from WVU Library Electronic Journals database

Blumberg, S. J., Bramlett, M. D., Kogan, M. D., Schieve, L. A., Jones, J. R., \& Lu. M. C. (2013).Changes in prevalence of parent-reported autism spectrum disorder in schoolaged U.S. children: 2007 to 2011 (Report No 65). Hyattsville, MD: National Center for Health Statistics

Bramlett, R. K. and Murphy, J. J. (1998) 'School Psychology Perspectives on 
Consultation: Key Contributions to the Field', Journal of Educational and Psychological Consultation 9:31-55

Brock, M. E., Huber, H. B., Carter, E. W., Juarez, A. P., \& Warren, Z. E. (2014). Statewide assessment of professional development needs related to educating students with autism spectrum disorders. Focus on Autism and Other Developmental Disabilities, Advance online publication. doi:10.1177/1088357614522290

Burns, M. K., \& Ysseldyke, J. E. (2009) Reported prevalence of evidence-based instructional practices in special education. Journal of Special Education, 43, 3- 11

Caplan, G. (1970). The theory and practice of mental health consultation. New York: Basic Books

Carter EW1, Lane KL, Cooney M, Weir K, Moss CK, Machalicek W. (2013). Parent assessments of self-determination importance and performance for students with autism or intellectual disability. Am J Intellect Dev Disabilities (1):16-31

Carnine, D. (2000). Why education experts resist effective practices (and what it would take to make education more like medicine). Thomas B. Fordham Foundation.

Centers for Disease Control and Prevention. (2014). Prevalence of autism spectrum disorder among children aged 8 years: Autism and developmental disabilities monitoring network, 11 sites, United States, 2010. MMWR Surveillance Summaries, 63, 121. 
Cochrane, W., \& Laux, J. (2008). A survey investigating school psychologists'

measurement of treatment integrity in school-based interventions and their beliefs about its importance. Psychology in the School, 45, 499-507.

Cohen, J. (1998). Statistical power analysis for the behavioral sciences ( $2^{\text {nd }}$ ed.). Hillsdale, NJ:

Erlbaum.

Cohen, H., \& Amerine-Dickens, M.S. Early Intensive Behavioral Treatment: Replication of the UCLA Model in a Community Setting.

Cook, B. G., \& Cook, S. C. (2011) Thinking and communicating clearly about evidencebased practices in special education. Council for Exceptional Children, Division for Research

Cook, L., \& Friend, M. (2010). The state of the art of collaboration of behalf of students with disabilities. Journal of Educational and Psychological Consultation, 20:1-8,

Cooper, J., Heron, T. E., \& Heward, W. L. (2007) Applied behavior analysis, 2nd Edition New Jersey: Merrill Prentice Hall.

Dammann, J. E., \& Vaughn, S. (2001). Science and sanity in special education. Behavior Disorders, 27, 21-29

Dane A.V. \& Schneider B.H. Program integrity in primary and early secondary prevention: Are implementation effects out of control? Clinical Psychology Review 1998; 18:23-45. [PubMed: 9455622]

Durlak, J.A., \& Dupree, E.P. (2008) Implementation matters: A review of research on 
The influence of implementation on program outcomes and the factors affecting implementation American Journal of Community Psychology 41, 327-350.

Dusenbury, L., Barrnigan, R., Falco, M., \& Hansen, W.B. (2003) A review of research on fidelity of implementation: Implications for drug abuse prevention in the school setting Health Education Research 18, 237-256

Eikeseth, S. (2001) Recent criticisms of the UCLA young autism project Behavioral Interventions 16 249-264

Eikeseth, S., Smith, T., \& Eldevik, E. J. S. (2002) Intensive behavioral treatment at school for 4 to 7 year old children with autism. Behavior Modification, 26(1), 4968. Retrieved from Sage Publications database.

Eldevik, S., Eikeseth, S., Jahr, E., \& Smith, T (2006). Effects of Low-Intensity Behavioral Treatment for Children with Autism and Mental Retardation Journal of Autism and Developmental Disorders, Vol. 36, No. 2, DOI 10.1007/s10803005-0058-x

Erchul, W. P., DuPaul, G. J., Grissom, P. F., Vile Junod, R. E., Jitendra, A. K., Mannella, M. C., Tresco, K. E., Flammer-Rivera, L. M., \& Volpe, R. J. (2007). Relationships among relational communication processes and consultation outcomes for students with Attention Deficit Hyperactivity Disorder School Psychology Review, 36,111-12

Flores, M. M., \& Ganz, J. B. (2007) Effectiveness of direct instruction for teaching statement inference, use of facts, and analogies to students with developmental disabilities and reading delays. Focus on Autism and Other Developmental Disabilities, 22(4), 244-251.

Friend, M., \& Cook, L. (2010). Interactions: Collaboration skills for school professionals 
( $6^{\text {th }}$ ed.). Upper saddle River, NJ: Pearson/Merrill.

Galloway, J., \& Sheridan, S. M. (1994). Implementing scientific practices through case studies: Examples using home-school interventions and consultation. Journal of School Psychology, 32, 385-413

Garbacz, S. Andrew; Woods, Kathryn E.; Swanger-Gagné, Michelle S.; Taylor, Ashley M.; Black, Kathryn A.; and Sheridan, Susan M., "The Effectiveness of a PartnershipCentered Approach in Conjoint Behavioral Consultation" (2008) Educational Psychology Papers and Publications. 83 http://digitalcommons.unl.edu/edpsychpapers/83

Garbacz, S.A., Rohlk, A.M., Swanger, M.S., Woods, K.E, Black, K.A., \& Sheridan, S.M Conjoint Behavioral Consultation: The Effectiveness of a Partnership Orientation. Paper presented at the annual conference of the National Association of School Psychologists March, 2006 Anaheim, CA

Gersten, R., \& Smith-Jones, J. (2001) Reflect Reflections on the research to practice gap. Teacher Education and Special Education, 24, 356-361.

Giangreco, M.F., Broer, S.F., Edelman, S. \& Doyle, M.B. (2001) Paraprofessional support of students with disabilities: Literature from the past decade. Exceptional Children, 68, 45-63.

Green, G. (2001). Behavior analytic instruction for learners with autism: Advances in stimulus control technology. Focus on Autism and Other Developmental Disabilities; Summer 2001; 16, 2; ProQuest Psychology Journals. p. 72-85.

Greenwood, C., \& Innocenti, M.S. (2005) Evidence-based interventions in school 
psychology: Conceptual foundations of the Procedural and coding manual of Division 16 and the society for the study of school psychology task force. School Psychology Quarterly, 17, 341-389.

Greenspan, S.I., \& Weider, S. (1997). Developmental patterns and outcomes in infants and children in relating and communicating: A chart review of 200 cases of children with autism spectrum diagnosis. Journal of Developmental and Learning Disorders, 1, 87-141.

Greenspan, S.I., \& Weider, S. (1999). A functional developmental approach to autism spectrum disorders. The Journal of the Association for Persons with Severe Handicaps 24, 147-161.

Gresham, F.M. Evolution of the treatment integrity concept: Current status and future directions (2009). School Psychology Review 38(4), 533-540

Gresham, F. M., MacMillian, D. L., Beebe-Frankenberger, M. E., \& Bocian, K. M. (2000). Treatment integrity in learning disabilities research: Do we really know how treatments are implemented. Learning Disabilities Research and Practice, $15,198-205$.

Gresham, F. M., \& Gansle, K. A. (2002). Does treatment integrity matter? A preliminary investigation of instructional implementation and mathematics performance. Journal of Behavioral Education, 11, 51-67.

Gresham, F.M., Gansle, K.A., Noell, G.H., Cohen, S., \& Rosenblum, S. (1993) Treatment integrity of school-based behavioral intervention studies: 1980-1990. School Psychology Review, 22, 254-272.

Gresham, F.M., MacMillan, D.L., Beebe-Frankenberger, M.E., \& Bocian, K.M. (2000) 
Treatment integrity in learning disabilities intervention research: Do we really know how treatments are implemented. Learning Disabilities Research \& Practice, 15, 198-205

Guli, L.A. Evidence-Based Parent Consultation with School-Related Outcomes. School Psychology Quarterly; Winter 2005; 20, 4

Gullan, R.L., Feinberg, B.E., Freedman, M.A., Jawad, A., \& Leff, S.A. Using Participatory Action Research to Design an Intervention Integrity System in the Urban Schools School Mental Health. 2009 September 1; 1(3): 118-130. Doi: 10.1007/s12310009-9006-9.

Gutkin, T. B. (1999). Collaborative versus directive/prescriptive/expert schoolbased consultation: Reviewing and resolving a false dichotomy. Journal of School Psychology, 37(2), 161-190.

Gutkin, T. B. (1986). Consultees' perceptions of variables relating to the outcomes of school-based consultation interactions. School Psychology Review, 15, 375-382.

Gutkin, T. B. (1993). Conducting consultation research In J. E. Zins, T. R. Kratochwill, \& S. N. Elliott (Eds.), Handbook of consultation services for children: Application in educational and clinical settings (pp. 227-248). San Francisco: Jossey-Bass.

Gutkin, T. B., \& Curtis, M. J. (1990) School-based consultation: Theory, techniques, and research. In T. B. Gutkin \& M. J. Curtis (Eds.). The handbook of school psychology (2nd ed., pp. 577-611). New York: Wiley.

Hall, L. J., Grundon, G. S., Pope, C., \& Romero, B. (2010). Training paraprofessionals to use behavioral strategies when educating learners with autism spectrum disorders across environments. Behavioral Interventions, 25, 37-51

Hagermoser-Sanetti, L.M., Gritter, K.L., \& Dobey, L.M. (2011) Treatment integrity 
interventions with children in the school psychology literature from 1995 to 2008. School Psychology Review 40(1) 72-84

Hess, K.L., Morrier, M.J., Heflin, L.J., \& Ivey, M. L. (2008). Autism treatment survey: Services received by children with autism spectrum disorders in public school classroom. Journal of Autism and Developmental Disorders, 38, 961-971.

Hineline, P.N., \& Axelrod. S. (2009) Evaluating intensive behavioral interventions for autism.Summary of research supported by the organization for autism research for the period January 2007 through September 2009.

Hineline, P. N. Jones, K. M. (2003). The aesthetics of behavioral interventions Invited Address presented at the Pennsylvania Association for Behavior Analysis Conference, Harrisburg, PA

Hirschtein, M.K., Edstrom, L.V., Frey, K. S., Snell, J.L., \& MacKenzie, E.P. (2007) Walking the talk in bullying prevention: Teacher variable implementation related to initial impact of the steps to respect program School Psychology Review 36, 3- 21

Horner, R., Carr, E., Halle, J., McGee, G., Odom, S., \& Wolery, M. (2005) The use of single-subject design research to identify evidence-based practice in special education. Exceptional Children, 71, 165-179.

Howard J.S., Sparkman C.R., Cohen H.G., Green G., Sanislaw H. A. (2005). Comparison of intensive behavior analytic and eclectic treatments for young children with autism. Research Developmental Disabilities, 26, 359-383.

Idol, L., Nevin, A., \& Paolucci-Whitcomb, P. (1995) The collaborative consultation Model. Journal of Educational and Psychological Consultation, 6(4), 347-361 
Ingersoll, B. (2011). The differential effect of three naturalistic language interventions on language use in children with autism. Journal of Positive Behavioral Interventions 13, 109-118

Ingersoll, B, \& Dvortesak, A. (2006). Including parent training in early childhood special education curriculum for children with ASD. Journal of Positive Behavioral Interventions, 8, 79-87

Israel, BA, Schulz, AJ, Parker, EA, Becker, AB. Review of community-based research: assessing partnership approaches to improve public health. Annu Rev Public Health. 1998; 19: 173-202.

Johnson, K. (2008). Precision Teaching Encyclopedia of Educational Psychology, 2, $809-813$

Jones, H.A., Clarke, A.Y., \& Power, T.J. (2008) Expanding the concept of intervention integrity: A multidimensional model of participant engagement In Balance, 23,

Joyce, B. \& Showers, B. (2002) Student achievement through staff development National College for School Leadership In Bruce Joyce and Beverley Showers, 2002, Designing Training and Peer Coaching: Our needs for learning, VA USA, ASCD

Kates-McElrath, K.K., \& Axelrod, S. (2005) Behavioral Intervention for Autism: A Distinction between Two Behavior Analytic Approaches The Behavior Analyst Today Volume 7, Number 2, Spring, 242

Katsiyannis, A., Hodge, J., \& Lanford, A. (2000) Paraeducators: Legal and Practice considerations. Remediation and Special Education 21, 297-292

Kazdin, A. E. (1982). Single-case research designs: Methods for clinical and applied settings. 
New York: Oxford University Press.

Kelleher, C., Riley-Tillman, C.T., \& Power, J.T An initial comparison of collaborative and expert-driven consultation on treatment integrity (8). J. Educational and Psychological Consultation, 18:294--324, 2008

Kretlow, A. G., \& Bartholomew, C. C. (2010). Using Coaching to Improve the Fidelity of Evidence-Based Practices: A Review of Studies. The Journal of the Teacher Education Division of the Council for Exceptional Children 33: 279-299

Kim, T., \& Axelrod, S. (2005). Direct Instruction: An educators' guide and plea for action. The Behavior Analyst Today 6(2)

Koegle, L., Matos-Fredeen, R.L., \& Koegel, R., Interventions for children with autism Spectrum disorders in inclusive school settings Cognitive and Behavioral Practice (2011), doi:10.1016/j.cbpra.2010.11.003

Koegel, L.K., Robinson, S., \& Koegel, R.L. (2008). Empirically supported intervention practices for autism spectrum disorders in school community settings: Issues and Practices

Kohler, F.W, Anthony, L.J., Steighner, S.A., \& Hoyson, M. (2001) Teaching social interaction skills in the integrated preschool: An examination of naturalistic tactics. Topics in Early Childhood Special Education, 21, 93-10

Kozloff, M.A., LaNunziata, L., Cowardin, J., \& Bessellieu, F.B. (2001) Direct Instruction: Its contributions to high school achievement. High School Journal, 84 (2), 54-72.

Kratochwill, T R. (1991) Defining constructs in consultation research: An important 
agenda in the 1990s. Journal of Educational and Psychological Consultation, 2, 291294.

Kratochwill, T. R., Bergan, J. R., Sheridan, S.M., \& Elliot, S.N. (1998) Assumptions of Behavioral Consultation: After all is said and done more has been done than said. Educational Psychology Papers and Publications Paper 60 http://digitalcommons.unl.edu/edpsychpapers/60

Kratochwill, T. R., Hitchcock, J., Horner, R. H., Levin, J. R., Odom, S. L., Rindskopf, D. M. \& Shadish, W. R. (2010) Single-case designs technical documentation. Retrieved from What Works Clearinghouse website: http://ies.ed.gov/ncee/wwc/pdf/wwc_scd.pdf.

Kratochwill, T. R., \& Stoiber, K.C. Uncovering critical research agendas for school psychology: Conceptual dimensions and future School Psychology Review; 2000; 29, 4; ProQuest Central pg. 591-603

Landa R, Garrett-Mayer E. 2006. Development in infants with autism spectrum disorders: A prospective study. J Child Psychiatry 47:629-638.

Lang, R., O’Reilly, M.F., Sigafoos, J., Machalicek, W., Rispoli, M., Shogran, K., \& Hopkins, S. (2010) Review of Teacher involvement in the applied intervention research for children with autism spectrum disorders. Education and Training in Autism and Developmental Disabilities, 45, 268-283

Leff, S.A., Hoffman, J.A., \& Gullan, R.L. Intervention Integrity: New Paradigms and Applications School Ment Health, 2009 September 1; 1(3): 103-106, doi: $10.1007 / s 12310-009-9013-x$

Leff, S.S., Thomas, D.E., Vaughn, N.A., Thomas, N. a. MacEvoy, J.P., Freedman. M.A., 
Abdul-Kabir, S., Woodlock, J., Guerra, T., Bradshaw, A.S., Woodburn, E. M, Myers, R.K., \& Fein, J. A. (2011) Using community-based participatory research to develop the partners youth violence prevention program. Progressive Community Health Partnership, 4(3): 207-216. http://ncbi.nih.gov/pmc/articles/PMC3074435/

Leff, S. S., Paskewich, B, Gullan, R. L, MacEvoy, J. P, Jawad, A. The preventing relational aggression in schools everyday (PRAISE) program: A preliminary evaluation of acceptability and impact. 2008 Manuscript in preparation

Lerman, D., Vorndran, L., \& Addison, L. (2004) Preparing teachers in evidence-based practices for young children with autism School Psychology Review, 33(4), 510526Lindsley, O. R. (1992) Precision teaching: discoveries and effects. The Journal of Applied Behavior Analysis, 25, 51-57.

Lindsley, O.R. (1990). Precision Teaching: By teachers for children. Teaching Exceptional Children, 22(3), 10-15

Loiacono, V. \& Feeley, K.M. Preparing Special Education Teachers in Evidence Based Strategies to Address the Needs of Students With Autism Spectrum Disorders. Draft

Lovaas, O. I. (1987). Behavioral treatment and normal intellectual and educational functioning in autistic children. Journal of Consulting and Clinical Psychology, 55, 3-9.

MacLeod, I. R., Jones, K. M., Somers, C. L. and Havey, J. M. (2001) ‘An Evaluation of the Effectiveness of School-Based Behavioral Consultation Journal of Educational and Psychological Consultation 12: 203-16.

McEachin J.J, Smith T, Lovaas O.I. Long-term outcome for children with autism who received early intensive behavioral treatment Am J Ment Retard 1993; 97:359Y372. 
McGee GG, Morrier MJ, Daly T. 1999. An incidental teaching approach to early intervention for toddlers with autism. J Assoc Pers Sev Handicaps 24:133-146.

Mcintyre, L.L, Gresham, F.M., DiGennaro, F.G., \& Reed, D.D., (2007). Treatment Integrity of School-Based Interventions with Children in the journal of Applied Behavior Analysis 1991-2005. Journal of Applied Analysis

Morgan, D. L. \& Morgan, R. K. (2009). Single-Case Research Methods for the Behavioral and Health Sciences SAGE Publications, Inc.

Morrier, M.J., Hess, K.L., \& Heflin, J.L. (2011). Teacher training for implementation of teaching strategies for students with autism spectrum disorders. Teacher Education and Special Education, 34, 119-132.

Mortenson, B. P., \& Witt, J. C. (1998). The use of weekly performance feedback to increase teacher implementation of a prereferral academic intervention. School Psychology Review, 27, 613-627.

Nastasi, B. K., Varjas, K., Schensul, S. L., Silva, K. T., Schensul, J.J., \& Ratnayake, P. (2000). The participatory intervention model: A framework for conceptualizing and promoting intervention acceptability. School Psychology Quarterly, 15, 207- 232.

National Institute of Neurological Disorders and Stroke (2008) Autism fact sheet Retrieved 9/8, 2008, from http://www.ninds.nih.gov/ disorders/autism/detail $\underline{\text { autism.html }}$

National Research Council (2001). Educating children with autism. Washington, DC: National Research Council

No Child Left Behind Act, Public Law 107-110, (2002). Retrieved February 1, 2013, From http://www.ed.gov/policy/elsec/leg/esea02/107-110.pdf 
Noell, G. H. (2008). Research examining the relationships among consultation process, treatment integrity and outcomes. In W. P. Erchul \& S. M. Sheridan (Eds.), Handbook of research in school consultation: Empirical foundations for the field. Mahwah, NJ: Erlbaum.

Noell, G.H., Witt, J.C., Slider, N.J., Connell, J.E., Gatti, S.L., Williams, K.L., Koenig, J.L., Jennifer L. Reseda, J.L., \& Duhon, G.J. Treatment implementation following behavioral consultation in schools: A comparison of three follow-up strategies. School Psychology Review, 2005, Volume 34, No. 1, pp. 87-106

Noell, G. H., \& Witt, J. C. (1996) A critical re-evaluation of five fundamental assumptions underlying behavioral consultation. School Psychology Quarterly, 11, 189-203.

Noell, G. H., \& Witt, J. C. (1999).When does consultation lead to intervention implementation? Critical issues for research and practice. The Journal of Special Education, 33, 29-35.

Odom, S.L., Brantlinger, E., Gersten, R., Horner, R. H., Thompson, B., \& Harris, K. (2005) Research in special education: Scientific methods and evidence-based Practices Exceptional Children 71(2), 137-148.

Odom, S. L., Collet-Klingenberg, L., Rogers, S. J.,M \& Hatton, D. D. (2010). Evidence-based practices in interventions for children and youth with autism spectrum disorders. Preventing School Failure, 54, 275-282. 
Office of Special Education Programs (OSEP) (2007) Students ages 6 through 21 served under IDEA, Part B, by disability category and state: Fall 2007. Retrieved

January 21, 2009, from https://www.ideadata.org/TABLES31ST/AR_1-3.htm

Ozonoff, S., \& Cathcart, K. (19980 Effectiveness of a home program intervention for young children with autism Journal of Autism and Developmental Disabilities, $\quad$ i28, 25-32

Perepletchikova F, Kazdin, A. E. Treatment integrity and therapeutic change: Issues and Research recommendations Clinical Psychology: Science and Practice 2005; 12(4):365-383.

Peterson, L., Homer, A. L. and Wonderlich, S. A. (1982) ‘The Integrity of Independent Variables in Behavior Analysis', Journal of Applied Behavior Analysis 15: 477-92.

Power, J. T., Blom-Hoffman, J., Clarke, A.T., Riley-Tillman, C.T., Kelleher, C., \& Manz, P.H. Reconceptualizing Intervention Integrity: A Partnership-Based Framework for Linking Research with Practice. Psychology in the Schools, Vol. 42(5), 2005

Power, T. J., Dowrick, P.W., Ginsburg-Block, M., \& Manz, P.H. (2004) Partnershipbased, community-assisted early intervention for literacy: An application of the participatory intervention model. Journal of Behavioral Education, 13, 93-115.

Pryzwansky, W. B. (1977). Collaboration or Consultation: Is There A Difference? The Journal of Special Education, 11 (2)

Reichle J, Wacker DP. 1993. Communicative alternatives to challenging behavior: Integrating functional assessment and intervention strategies, Vol. 3. Baltimore: Brookes. 
Riley-Tillman, T.C., \& Chafouleas, S.M., (2003) Using interventions that exist in the natural environment to increase treatment integrity and social influence in consultation. Journal of Educational and Psychological Consultation 14(2), 139-156.

Rogers, S.J., Hall, T., Osaki, D., Reavon, J., \& Herbison, J. (2001) The Denver Model: A comprehensive integrated educational approach for young children with autism and their families. In J. S. Handelman \& S. L. Harris (Eds.) Preschool education programs for children with autism (pp. 95-133). Austin, TX. Pro-ed.

Rosales-Ruiz, J., \& Baer, D. M. (1997). Behavioral cusps: A developmental and pragmatic concept for behavior analysis. Journal of Applied Behavior Analysis, 30, 533-544.

Rosenfield, S. Best practices in instructional consultation and instructional teams. Best Practices in School Psychology V Chapter 103, Volume 2

Sallows, G. O., \& Graupner, T. D. (2005) Intensive behavioral treatment for children with Autism: Four-year outcome and predictors. American Journal on Mental Retardation, 110, 417-437.

Sanetti, L.M.H., \& Kratochwill, T.R. (2008) Toward developing a science of treatment integrity: Introduction to the special series. School Psychology Review 38 445-459

Schulte, A.C. \& Osborne, S.S. (2003) When assumptive worlds collide: A review of definitions of collaboration in consultation. Journal of Educational and Psychological consultation, 14(2), 109-138

Schreibman, L. \& Ingersoll, B. (2005) Behavioral interventions to promote learning in individuals with autism F. Volkmar, R. Paul, A. Klin, R and Cohen (Eds.). Handbook of autism and pervasive developmental disorders $\left(3^{\text {rd, Edition }}\right)$ 
Hoboken, NJ: John Wiley \& Sons, Inc. (pp. 882-89)

Scruggs, T.E., \& Mastropieri, M.A. (2001). How to summarize single participant research: Ideas and applications. Exceptionality, 9, 227-244

Simpson, R. L., (2005). Evidence-based practices and students with autism spectrum disorder Focus on Autism and other Developmental Disorders, 20, 140-149

Simpson, R.L., (2001). ABA and students with autism spectrum disorders: Issues and considerations for effective practice. Focus On Autism and Other Developmental Disorders, 16(2), 68-71

Shadish, W. R., Cook, T. D., \& Campbell, D. T. (2002). Experimental and quasi-experimental designs for generalized causal inference. Boston: Houghton Mifflin

Sheridan, S. M. "Conceptual and Empirical Basis of Conjoint Behavioral Consultation” (1997), Educational Psychology Papers and Publications, Paper 59, http://digitalcommons.unl.edu/edpsychpapers/59

Sheridan, S. M., \& Cohen, R. J., “Consultation with School Personnel” (2004), Educational Psychology Papers, Paper 32 $\underline{\text { http://digitalcommons.unl.edy/edpsychpapers/32 }}$

Sheridan, S. M., Clarke, B. L., \& Burt, J. D. (2008) Conjoint behavioral consultation: What do we know and what do we need to know? In W. P. Erchul \& S. M. Sheridan (Eds.), Handbook of research in school consultation: Empirical foundations for the field. Mahwah, NJ: Erlbaum.

Sheridan, S. M.; Clarke, B.L.; Burt, J.D.; Swanger, M.S.; Olson, S.; Garbacz, Stanley A 
Marti, D.C.; Rohlk, A.; Black, K.; Woods, K.; and Magee, K., "Is conjoint behavioral consultation partnership-centered: An exploratory analysis." (2005). Posters, Addresses, \& Presentations from CYFS Paper $30 \mathrm{http}: / /$ digitalcommons.unl.edu/cyfsposters/30

Sheridan, S. M., Eagle, J. W., Cowan, R. J., \& Mickelson, W. (2001). The effects of conjoint behavioral consultation results of a four year investigation. Journal of School Psychology, 39, 361-385.

Sheridan, S. M., Marti, D. C., Clarke, B. L., Burt, J. D., Black, K. A., Rohlk, A. M., Woods, K. E., Garbacz, S. A., Swanger, M. S., Olson, S. C., \& Magee, K. (2005). Is conjoint behavioral consultation partnership centered? An exploratory analysis Paper presented at the annual conference for the National Association of School Psychologists, Atlanta, GA.

Sheridan, S.M., Richards, J.R., \& Smoot, T.Y. (2000). School Consultation Published in Encyclopedia of Psychology (2000), Alan E. Kazdin, Editor in Chief, volume 7, pages 167-170. This paper is posted at Digital Commons @ University of Nebraska Lincoln. http://digitalcommons.unl.edu/edpsychpapers

Sheridan, S. M., Welch, M. and Orme, S. F. (1996) 'Is Consultation Effective? A Review of Outcome Research', Remedial and Special Education 17: 341-354

Simpson, R. (2005). Evidence-based practice and students with autism spectrum disorder Focus on Autism and other Developmental Disorders, 20, 140-149.

Skinner, B.F. (1957). Verbal Behavior. Englewood Cliffs, NJ: Prentice Hall

Smith, T. (2001). Discrete trial training in the treatment of autism Focus on Autism and Other Developmental Disabilities, 16, 86-92.

Smith, T., Eikeseth, S., Klevstrand, M., \& Lovaas, O. I. (1997) Intensive behavioral 
treatment for preschoolers with severe mental retardation and pervasive developmental disorder. American Journal on Mental Retardation, 102, 238-249.

Smith, T., Groen, A. D., \& Wynn, J. W. (2000) Randomized trial of intensive early intervention for children with pervasive developmental disorder. American Journal on Mental Retardation, 105, 269-285.

Smith, T., Greenspan, S., \& Wieder, S. (2001) What is the DIR ${ }^{\circledR} /$ Floortime $^{\mathrm{TM}}$ Model? Interdisciplinary Council on Developmental and Learning Disorders (ICDL)

Snell, M. E. (2003). Applying research to practice: The more pervasive problem? Research and Practice for Persons with Severs Disabilities, 28, 143-147

Snell, M. E., \& Janney, R. E. (2000) Teacher's problem-solving about children with moderate and severs disabilities in elementary classrooms. Exceptional Children66, 472490

Swanger-Gagné, M. S., Garbacz, S. A., Toland, M. D., Sheridan, S. M., Witte, A Glover, T. A., et al. (2007, August). Treatment implementation integrity of interventions facilitated by conjoint behavioral consultation. Paper presented at the annual meeting of the American Psychological Association, San Francisco, CA.

Swanger-Gagne MS, Garbacz SA, Sheridan SM. Intervention implementation integrity within a behavioral consultation model: Strategies for working with families at risk. School Mental Health. 200910.1007/s12310-009-9012-y

Swanger-Gagne, Michelle, "The Influence of the Family Context and Intervention Implementation Integrity on Child Behavior during Conjoint Behavioral Consultation" (2009) Open Access Theses and Dissertations from the College of Education and Human Sciences Paper 48 http://digitalcommons.unl.edu/cehsdiss/48 
The National Autism Center's National Standards Project: Findings and conclusions addressing the needs for evidence-based practice guidelines for autism spectrum disorders (Eds.) Howard, H.A., Ladew, B.S., \& Pollack, E.G.

Tucci, V., Hursh, D., Laitinen, R., \& Lambe, A. (2005) Competent Learner Model for Individuals with Autism /PDD Exceptionality, 13(1), 55-63

Tucci, V., Hursh, D., \& Laitinen, R. (2004) The competent learner model: A merging of applied behavior analysis, direct instruction, and precision teaching. In D. J. Moran, \& R. W. Malott (Eds.), Evidence based educational methods (pp. 109-126). San Diego, CA: Elsevier Academic Press.

Tucci, V., Swatsky, B., Kirsten Yurich, K., Scutta, C., \& McMahon, S. National How the CLM Engineers 'Discovery Learning' Opportunities for Learners and Instructors. Autism Conference 2011State College, PA.

Warash, B., Curtis, R., Hursh, D., \& Tucci, V. (2008) Skinner meets Piaget on the Reggio playground: Practical synthesis of applied behavior analysis and developmentally appropriate practice orientations. Journal of Research in Childhood Education, 22(4), 441-453.

Watkins, C. (1997). Project Follow Through: A case study of contingencies influence instructional practices of the educational establishment. Cambridge, MA: Cambridge Center for Behavioral Studies

Wenger, R.D. (1979). Teacher response to collaborative consultation Psychology in the Schools 16, 127-131

West, J. F., \& Idol, L. (1993). Counselor as consultant in the collaborative school. Journal of 
Counseling and Development 71, 678-682

What Works Clearinghouse. (2008). What Works Clearinghouse evidence standards for reviewing studies. Retrieved October 10, from http//ies.ed,gov/ncee/pdf/study_standard-final.pdf.

Wickstrom, K.F., Jones, K.M., LaFleur, L.H., \& Witt, J.C. (1998) An analysis of treatment integrity in school-based behavioral consultation. School Psychology Quarterly, 13, 141-154.

Wilkinson, L.A. Monitoring Treatment Integrity: An Alternative to the 'Consult and Hope' Strategy in School-Based Behavioural Consultation School Psychology International 2006 27: 426 DOI: 10.1177/0143034306070428

Witt, J. C. (1990). Collaboration in school based consultation: Myth in need of data. Journal of Educational and Psychological Consultation 1(3), 367-370.

Witt, J. C., Gresham, F. M., \& Noell, G. H. (1996a) What's behavioral about behavioral consultation? Journal of Educational and Psychological Consultation,

Wolery, M., Barton, E. E., \& Hine, J. F. (2005) Evolution of applied behavior analysis in The treatment of individuals with autism Exceptionality, 13(1), 11-23 Retrieved 4/1, 2013 from http://web.ebscohost.com/ehost/

Yell, M. L., Drasgow, E., \& Lowrey, K. A. (2005). No child left behind and students with Autism spectrum disorders Focus on Autism and Other Developmental Disabilities, 20(3), 130-139. Retrieved from WVU Library Electronic Journals database 


\section{Appendix A}

\section{The Partnership Assessment in community-based Research (PAIR) Measure}

The goal of this questionnaire is to understand the relationship between researchers and school/community members working together on projects. Below is a list of sentences that describe how researchers and school/community members work together to do research in the community. The term "partner" is used to describe the person you are working with in your research.

Before completing the measure, pick ONE partner who best represents the relationship between you and the organization with which you are partnering. Please pick ONE partner even if you work with multiple partners. When completing all items, please have this person in mind and consider the whole length of time you have worked with this person.

My Name: My Partner's Name:

My Organization: My Partner's Organization:

I am a:

Researcher

Community/School Member

My Partner is a: $\quad$ Researcher Community/School Member

How long have you worked with this partner? :

Less than 1 year 1-2 years 3-5 years

Over 5 years (indicate how many:

How much does the relationship you have with this partner affect how you feel about your partner's organization? Not at all Very little Somewhat Very Much Greatly

Read each phrase and circle the one answer that best describes the relationship between you and your partner on a scale of $1=$ "Almost Never True," 2 = "Occasionally True," 3 = "Sometimes True," 4 = "Often True," or 5 = "Almost Always True" for you and this partner. Please consider the same partner for each item.
1
2
3
4
5

Almost Never True Occasionally True Sometimes True Often True Almost Always True

1. My partner discusses ideas with me.

2. My partner shares resources (e.g. materials, space, etc...) with me when appropriate.

3. I believe my partner tries to improve our partnership.

4. There is open communication between me and my partner.

5. I believe my partner values my views. 
6. I try to understand the strengths and difficulties of my partner are setting.

7. I discuss ideas with my partner.

8. I believe my partner tries to understand the strengths and difficulties of my setting.

9. My partner and I divide responsibilities in a way that is acceptable to me.

10. My partner and I contribute to research through our partnership.

11. My partner and I talk about how our partnership is working.

12. I share resources (e.g. materials, space, contacts, etc...) with my partner when appropriate.

13. My partner talks with me when problems arise.

14. My partner and I work together to make decisions when appropriate.

15. I respect my partner.

16. The community benefits from this partnership.

17. My organization benefits from this partnership.

18. I feel trusted by my partner.

19. The relationship is worth the amount of time I invest in it.

20. I talk with my partner when problems arise.

21. I benefit personally from this partnership.

22. My partner and I share responsibility for making decisions when appropriate.

23. My partner and I are committed to making our partnership work well.

24. I trust my partner.

25. I value my partner's views.

26. I benefit professionally from this partnership.

27. I believe my partner tries to understand the culture of my organization/community.

28. My partner and I work together to create our goals.

29. I feel respected by my partner.

30. I try to understand the culture of my partner's organization/community.

31. I try to improve our partnership. 
32. Will the process of filling out this questionnaire influence how you will work with your partner? If so, how?: 


\section{Appendix B}

\section{Instructional Session Performance Checklist}

\section{USED MATERIALS (Curriculum)}

- Necessary materials were in place

○ Materials were within easy reach

- Selected materials were matched to The instructional routine

- Other materials did not distract L

\section{POSITIONED (Physical Structure)}

- Selected appropriate position

- Materials were clearly visible to $\mathrm{L}$

○ Teacher could monitor L performance

\section{PROMPTED/FADED Assistance (T Delivery)}

○ Prompted as suggested to get Independent responding

- Attempted to FADE or faded the prompts within session

\section{ENDED Session (Teacher Delivery)}

- Completed required \# of minutes, tasks or responses

\section{(INSTRUCTED) Presented Instruction correctly (delivery)}

Showed or told learner what's expected

Delivered instruction as suggested

Paused no more than 2 seconds for $\mathrm{L}$ response

Paced delivery appropriately foe participation

Hovered to assure success

Altered format to accommodate learner's level

Delivered correct instructional routine

Delivered type of correction procedure suggested

\section{REINFORCED L Behavior (Teacher Delivery)}

Reinforced L behavior as suggested (crf, int)

Used int. reinforcement with FITM items

Delivered or changed reinforcement Based on L performance

\section{Continued task presentation when undesirable Behaviors occur}

Withheld reinforcement For prompted responses 


\section{Appendix C}

Dimensions and Definitions of the Partnership Assessment in Community-based Research

(PAIR)

\begin{tabular}{|c|c|}
\hline Dimension & Definition \\
\hline $\begin{array}{l}\text { Communication: } \\
\qquad 1,4,7,13,20\end{array}$ & $\begin{array}{l}\text { Communication involves open dialogue between partners, including an } \\
\text { honest exchange of ideas, conversations about issues that arise, and the } \\
\text { resolution of conflicts through discussions. }\end{array}$ \\
\hline $\begin{array}{l}\text { Collaboration: } \\
2,9,12,14,22,28\end{array}$ & $\begin{array}{l}\text { Collaboration involves the demonstration of partners working together } \\
\text { in an equitable manner by sharing leadership and resources, engaging in } \\
\text { joint decision making, dividing responsibilities, and collaboratively } \\
\text { determining goals. }\end{array}$ \\
\hline $\begin{array}{c}\text { Partnership Values: } \\
\text { 3,5,6,8,15,18,24,25, } \\
27,29,30\end{array}$ & $\begin{array}{l}\text { Partnership Values comprise core values that characterize the } \\
\text { relationship between partners, specifically mutual trust, mutual respect, } \\
\text { valuing of the other partner's perspective, appreciation of the strengths } \\
\text { and difficulties of the other partner's setting, and dedication to } \\
\text { understanding the culture of the other partner's } \\
\text { organization/community }\end{array}$ \\
\hline $\begin{array}{c}\text { Benefits: } \\
10,16,17,19,21,26\end{array}$ & $\begin{array}{l}\text { Benefits include tangible benefits stemming from the partnership, } \\
\text { specifically personal, professional, organizational, and community } \\
\text { benefits, as well as advancement of scientific knowledge }\end{array}$ \\
\hline $\begin{array}{l}\text { Evaluation: } \\
11,23,31\end{array}$ & $\begin{array}{l}\text { Evaluation involves a commitment from the partners to engage in } \\
\text { ongoing assessment of how the partnership is working and to use that } \\
\text { information to inform and implement improvement efforts. }\end{array}$ \\
\hline
\end{tabular}

(Adapted from Arora, P., et al., in press) 
